\title{
Observation of intermediate states of the human prion protein by high pressure NMR spectroscopy
}

\author{
Norman Kachel ${ }^{1}$, Werner Kremer ${ }^{1}$, Ralph Zahn ${ }^{2,3}$ and \\ Hans Robert Kalbitzer*1
}

Address: ${ }^{1}$ Institut für Biophysik und Physikalische Biochemie, Universität Regensburg, Universitätsstr. 31, 93053 Regensburg, Germany, ${ }^{2}$ Institute of Molecular Biology and Biophysics, ETH Hönggerberg, CH-8093 Zürich, Switzerland and ${ }^{3}$ Alicon AG, Wagistrasse 23, 8952 Zürich-Schlieren, Switzerland

Email: Norman Kachel - norman.kachel@biologie.uni-regensburg.de; Werner Kremer - werner.kremer@biologie.uni-regensburg.de; Ralph Zahn - info@alicon.ch; Hans Robert Kalbitzer* - hans-robert.kalbitzer@biologie.uni-regensburg.de

* Corresponding author

Published: 17 July 2006

BMC Structural Biology 2006, 6:16 doi:10.1186/1472-6807-6-16
Received: 22 March 2006

Accepted: 17 July 2006

This article is available from: http://www.biomedcentral.com/1472-6807/6/16

(c) 2006 Kachel et al; licensee BioMed Central Ltd.

This is an Open Access article distributed under the terms of the Creative Commons Attribution License (http://creativecommons.org/licenses/by/2.0), which permits unrestricted use, distribution, and reproduction in any medium, provided the original work is properly cited.

\begin{abstract}
Background: Prions as causative agents of transmissible spongiform encephalopathies (TSEs) in humans and animals are composed of the infectious isomer, PrPSc, of the cellular prion protein, $\operatorname{PrPC}$. The conversion and thus the propensity of $\operatorname{PrPC}$ to adopt alternative folds leads to the species-specific propagation of the disease. High pressure is a powerful tool to study the physicochemical properties of proteins as well as the dynamics and structure of folding intermediates.
\end{abstract}

Results: Conformational intermediates of the human prion protein huPrPC were characterized by a combination of hydrostatic pressure (up to $200 \mathrm{MPa}$ ) with two-dimensional NMR spectroscopy. All pressure effects showed to be reversible and there is virtually no difference in the overall pressure response between the folded core of the $\mathrm{N}$-terminal truncated huPrPC$(|2|-230)$ and the full-length huPrPC (23-230). The only significant differences in the pressure response of full-length and truncated PrP suggest that EI68, HI87, TI92, E207, E2II and Y226 are involved in a transient interaction with the unfolded $\mathrm{N}$-terminus. High-pressure NMR spectroscopy indicates that the folded core of the human prion protein occurs in two structural states $N_{1}$ and $N_{2}$ in solution associated with rather small differences in free enthalpies $(3.0 \mathrm{~kJ} / \mathrm{mol})$. At atmospheric pressure approximately $29 \%$ of the protein are already in the pressure favored conformation $\mathrm{N}_{2}$. There is a second process representing two possible folding intermediates $I_{1}$ and $I_{2}$ with corresponding average free enthalpies of 10.8 and $18.6 \mathrm{~kJ} / \mathrm{mol}$. They could represent preaggregation states of the protein that coexist at ambient pressure with a very small population of approximately $1.2 \%$ and less than $0.1 \%$. Further the pressure response of the $\mathrm{N}$-terminus indicates that four different regions are in a fast equilibrium with non-random structural states whose populations are shifted by pressure.

Conclusion: We identified pressure stabilized folding intermediates of the human prion protein. The regions reflecting most strongly the transition to the intermediate states are the $\beta \mathrm{I} / \alpha \mathrm{l}$-loop and the solvent exposed side of $\alpha 3$. The most pressure-sensitive region (representing mainly intermediate $I_{I}$ ) is the loop between $\beta$-strand I and $\alpha$-helix I (residue I39-I4I), indicating that this region might be the first entry point for the infectious conformer to convert the cellular protein. 


\section{Background}

Transmissible spongiform encephalopathies (TSEs), or prion diseases, are infectious fatal disorders of the central nervous system (CNS) which include Creutzfeldt-Jakob disease, Gerstmann-Sträussler-Scheincker syndrome, fatal familial insomnia, and kuru in humans, bovine spongiform encephalopathy in cattle, scrapie in sheep, and chronic wasting disease in deer and elk [1]. They are associated with the accumulation of an oligomeric conformational scrapie isomer, PrPSc, of the host-encoded monomeric prion protein $\mathrm{PrPC}$ [2]. According to the "protein only" hypothesis, $\mathrm{PrPSc}$ is the sole component of transmissible prions [3]. One of the main supports for this hypothesis is the finding that PrP knockout $\left(P R N P^{0 / 0}\right)$ mice are completely protected against scrapie disease and fail to propagate prions $[4,5]$ and that introduction of murine PRNP transgenes into these mice restores the susceptibility to prions [6]. The formation of $\mathrm{PrPSc}^{\mathrm{S}}$ involves a conformational switch by which $\mathrm{PrPC}^{\mathrm{C}}$ is transformed into the PrPSc conformation with $\mathrm{PrPSc}^{\mathrm{S}}$ as template [7]. Recently Legname et al. succeeded in their attempt to form infectious PrPSc from recombinant $\mathrm{PrPC}^{\mathrm{C}}$ without the use of infectious material, which strongly supports the "protein only" hypothesis [8]. Puzzling to this hypothesis is the existence of a wide variety of distinct so-called prion strains with differing infectivity and related to them the mechanism of the species barrier, i.e., the degree of the interspecies infectivity of a prion strain [9]. Primarily, the differences in $\mathrm{PrPSc}^{\mathrm{Sc}}$ amino acid sequence related to heterology of the PrP genotype may account for the formation of distinct prion strains and for the species barrier [10]. For this reason hamster prions are usually not infectious to wild-type mice and there is a moderate species barrier for transmission of mouse prions to hamster. However, formation of distinct prion strains is even known, when the strains have identical primary structure and the hosts are genetically identical [11]. In this sense a recent article of the Prusiner group [12] provides evidence that $\mathrm{PrPSc}$ conformation and species barrier may be independent of the infectious isomer and the degree of homology between the PrP of the donor and that of the host. The species barrier should better be defined as the inability of the host to replicate the conformation of the infectious isomer and is broken only by altering the original and generating a conformational distinct isoform [12]. The fact that prion strains are encoded in the conformation of the protein has recently been proven for yeast prions $[13,14]$. Several lines of evidence suggest that this is also true for mammalian PrP, as reviewed by Chien et al. [15]. More recently Vanik et al. [16] showed that sequencebased barriers that prevent cross-seeding between prion proteins from different species can be bypassed in vitro by a template-induced adaptation process leading to the emergence of new strains of prion fibrils. Structural work should elucidate and identify the properties that deter- mine the species barrier and the reproducibility or lack of reproducibility of a prion strain in a given host.

Structures of the cellular prion proteins from different species are known, among these hamster [17,18], human [19-21] and bovine [22]. Acidic pH can induce a scrapielike unfolding intermediate of the prion protein [23] and was shown to convert the human prion protein reversibly between native monomeric and fibrilogenic conformations [24]. The application of hydrostatic pressure is known to stabilize folding intermediates and was applied to the study of aggregates and amyloids [25-28]. Recently a number of groups performed high pressure experiments on mammalian prion protein [29-33]. The combination of high hydrostatic pressure with high resolution NMR spectroscopy allows the observation of pressure induced structural changes and shifts of conformational equilibria as well as local instabilities of the protein at atomic resolution. Kuwata et al. [34] used high pressure NMR spectroscopy to stabilize a locally disordered conformer of the hamster prion protein.

Here we report results from high pressure NMR spectroscopy on two isoforms of the human prion protein, $h u \operatorname{PrP}(121-231)$ and $h u \operatorname{PrP}(23-231)$, at $\mathrm{pH} 4.8$ and 293 $\mathrm{K}$ in the pressure range from 0.1 to $200 \mathrm{MPa}$. The application of pressure potentially allows detecting structural intermediates of PrP which may be important for the transformation process between cellular and infectious scrapie-type protein.

\section{Results \\ General pressure effects on full length and truncated human prion protein}

1D ${ }^{1} \mathrm{H}$ - and 2D ${ }^{1} \mathrm{H}-{ }^{15} \mathrm{~N}-T R O S Y$ NMR spectra of two different constructs of the ${ }^{15} \mathrm{~N}$ enriched human prion protein, $h u \operatorname{PrP}(23-230)$ and $h u \operatorname{PrP}(121-230)$, were recorded at pH 4.8 (acetate buffer) at various pressures. We used solution conditions identical to those used for the structure determination [19]. Particularly for $h u \operatorname{PrP}(23-230)$ slightly acidic $\mathrm{pH}$ is necessary because the protein aggregates at neutral $\mathrm{pH}$ [35]. The shorter construct $h u \operatorname{PrP}(121-230)$ contains essentially the C-terminal folded part of the protein, the longer construct $h u \operatorname{PrP}(23-$ 230) in addition the unfolded N-terminus of the prion protein. Under theses conditions they showed nearly identical and completely reversible pressure responses in the range from 0.1 to $200 \mathrm{MPa}$. At $293 \mathrm{~K}$ we applied hydrostatic pressures in steps of $0.1,50,100,125,150$, 175 and $200 \mathrm{MPa}$ to both, huPrP(23-230) and $h u \operatorname{PrP}(121-230)$. Increasing pressure results in chemical shift changes of all resonances. In addition, in the TROSYHSQC spectra the increased pressure leads to a decrease of the signal volumes of a number of resonances. Some of the signals disappear completely from the spectra while 
others show no significant volume change as described below (see section "pressure response of cross peak volumes").

\section{Pressure dependence of the chemical shifts in the truncated and full length prion protein}

In general, the pressure response of proteins is anisotropic and the chemical shift changes induced by the local and global conformational changes are a non-linear function of the pressure. Traditionally, the pressure dependence is described by the zero-order coefficient $\delta_{0}\left(p_{0}, T_{0}\right)$, the first order coefficient $\mathrm{B}_{1}$ and the second order coefficient $\mathrm{B}_{2}$ of a Taylor expansion around the pressure $p_{0}$ and the temperature $T_{0}$ (see eq. 1 ). When the pressure effects are assumed to be composed of two contributions, an unspecific effect as observed in random-coil peptides and a specific, structure dependent effect, then the influence of these effects on the Taylor coefficients can be assumed as additive as long as the two events are not or only weekly coupled (see Methods). In this case, the corrected, conformation dependent pressure (Taylor) coefficients $\mathrm{B}_{1}{ }^{*}$ and $\mathrm{B}_{2}{ }^{*}$ can be obtained by subtracting the corresponding pressure coefficients from random-coil peptides. Random-coil pressure coefficients are available for the ${ }^{1} \mathrm{H}$-shifts from a study of the model peptides Gly-Gly-X-Ala peptides [36] but not for the ${ }^{15} \mathrm{~N}$-shifts.

The first order conformation dependent pressure $\left|B_{1}{ }^{*}(H)\right|$ for the ${ }^{1} \mathrm{H}^{\mathrm{N}}$ shifts and of the uncorrected pressure coefficient $\left|B_{1}(N)\right|$ of the ${ }^{15} \mathrm{NH}^{\mathrm{H}}$ chemical shift as a function of the primary and the secondary structure are displayed in Fig. 1 for the full length protein $h u \operatorname{PrP}(23-230)$. Analogously, the second order coefficients $\left|B_{2}{ }^{*}(H)\right|$ and $\left|B_{2}(N)\right|$ are plotted as a function of the sequence position in Fig. 2. The mean first and second order pressure coefficients $\left|B_{1}{ }^{*}(H)\right|,\left|B_{1}(N)\right|,\left|B_{2}{ }^{*}(H)\right|$, and $\left|B_{2}(N)\right|$ are 0.38 $\mathrm{ppm} / \mathrm{GPa}, 3.35 \mathrm{ppm} / \mathrm{GPa}, 1.23 \mathrm{ppm} / \mathrm{GPa}^{2}$, and 5.70 $\mathrm{ppm} / \mathrm{GPa}^{2}$.

A similar shift pattern is obtained for the truncated prion protein (data not shown) in the regions which are common to both proteins. However, the mean first and second order pressure coefficients $\left|B_{1}{ }^{*}(H)\right|,\left|B_{1}(N)\right|$, $\left|B_{2}{ }^{*}(H)\right|$, and $\left|B_{2}(\mathrm{~N})\right|$ are with $0.57 \mathrm{ppm} / \mathrm{GPa}, 3.35 \mathrm{ppm} /$ $\mathrm{GPa}, 1.69 \mathrm{ppm} / \mathrm{GPa}^{2}$, and $7.29 \mathrm{ppm} / \mathrm{GPa}^{2}$ significantly larger than in the full length protein. This is different when corresponding regions are compared since the pressure effects are much smaller in unfolded regions of the protein which contribute much more to the mean values in the full length protein. For the folded part of the full length protein one obtains mean values for $\left\langle\left|B_{1}{ }^{*}(H)\right|>\right.$, $<\left|B_{1}(N)\right|>,<\left|B_{2}{ }^{*}(H)\right|>$, and $<\left|B_{2}(N)\right|>0.57 \mathrm{ppm} / \mathrm{GPa}$, $3.33 \mathrm{ppm} / \mathrm{GPa}, 1.60 \mathrm{ppm} / \mathrm{GPa}^{2}$, and $6.62 \mathrm{ppm} / \mathrm{GPa}^{2}$, respectively.
If one takes the region common in the two proteins then the averages of the pressure coefficients are almost identi$\mathrm{cal}$, that is the $\mathrm{N}$-terminus does not significantly influence the average pressure response of the folded part. The correlation coefficient for the first order proton and nitrogen coefficients $B_{1}{ }^{*}(H)$ and $B_{1}(N)$ of the two proteins is 0.71 and 0.73 , respectively, indicating also a quantitative agreement of the parameters in the two proteins. For the correlation coefficients of, $B_{2}{ }^{*}(H)$, and $B_{2}(N)$ one obtains with 0.34 and 0.63 smaller correlations in the two proteins. This is mainly due to the relatively large errors involved in the calculation of the Taylor pressure coefficients. In contrast, the direct correlation of the experimental chemical shift changes $\Delta \delta(p)$ (see Methods) is much higher. The mean value of these correlation coefficients for each residue of $h u \operatorname{PrP}(23-230)$ to its corresponding residue in $h u \operatorname{PrP}(121-230)$ is 0.86 for the amide protons and 0.93 for the amide nitrogen atoms.

Although the general pressure response of the folded core is very similar in the full length and the truncated $h u \operatorname{PrP}$ there are some residues where clearly different responses can be observed (Fig. 3). The chemical shift differences already existing for Glu168, His187, Thr192, Glu207, Glu211 and Tyr226 at ambient pressure become larger with increasing pressure.

In the structured core (amino acid 121-230) of full length and truncated $h u \mathrm{PrP}$ most residues shift with increasing pressure (Figs. 1 and 2). For identifying residues that behave differently to the majority of the peaks one can select those which display first or second order pressure coefficients which are larger or smaller than the average by a standard deviation (SD). Since large chemical shift changes are strongly correlated with large conformational changes, residues with pressure coefficients larger than average plus one SD are most probably involved in strong conformational changes. Accordingly, residues with pressure coefficients smaller than average minus one SD represent regions of small inferred conformational changes. The residues M129, F141, Q186, H187, T188, V189, K194, E196, E207, V210, E211, E219 and R220 display first order pressure coefficients $\left|B_{1}{ }^{*}(H)\right|$ and G131, I139, H140, C179, T183, T188, T191, K194, G195, N197, F198, T199, D202 and M205 $\left|B_{1}(N)\right|$ which are significantly larger than the average in this region (by one standard deviation) for $h u \operatorname{PrP}(121-230)$. The largest pressure induced chemical shift changes of amide proton resonances are observed in the loop between strand $\beta 1$ (Y128 to G131) and helix $\alpha 1$ (D144 to M154), in the loop connecting helix $\alpha 2$ (N173 to K194) and $\alpha 3$ (E200 to R228), as well as in regions of helix $\alpha 2$ and $\alpha 3$. Generally, the differences of the pressure dependence of the chemical shifts along the protein sequence are much less pronounced for the amide nitrogen atoms than for the amide protons. The 

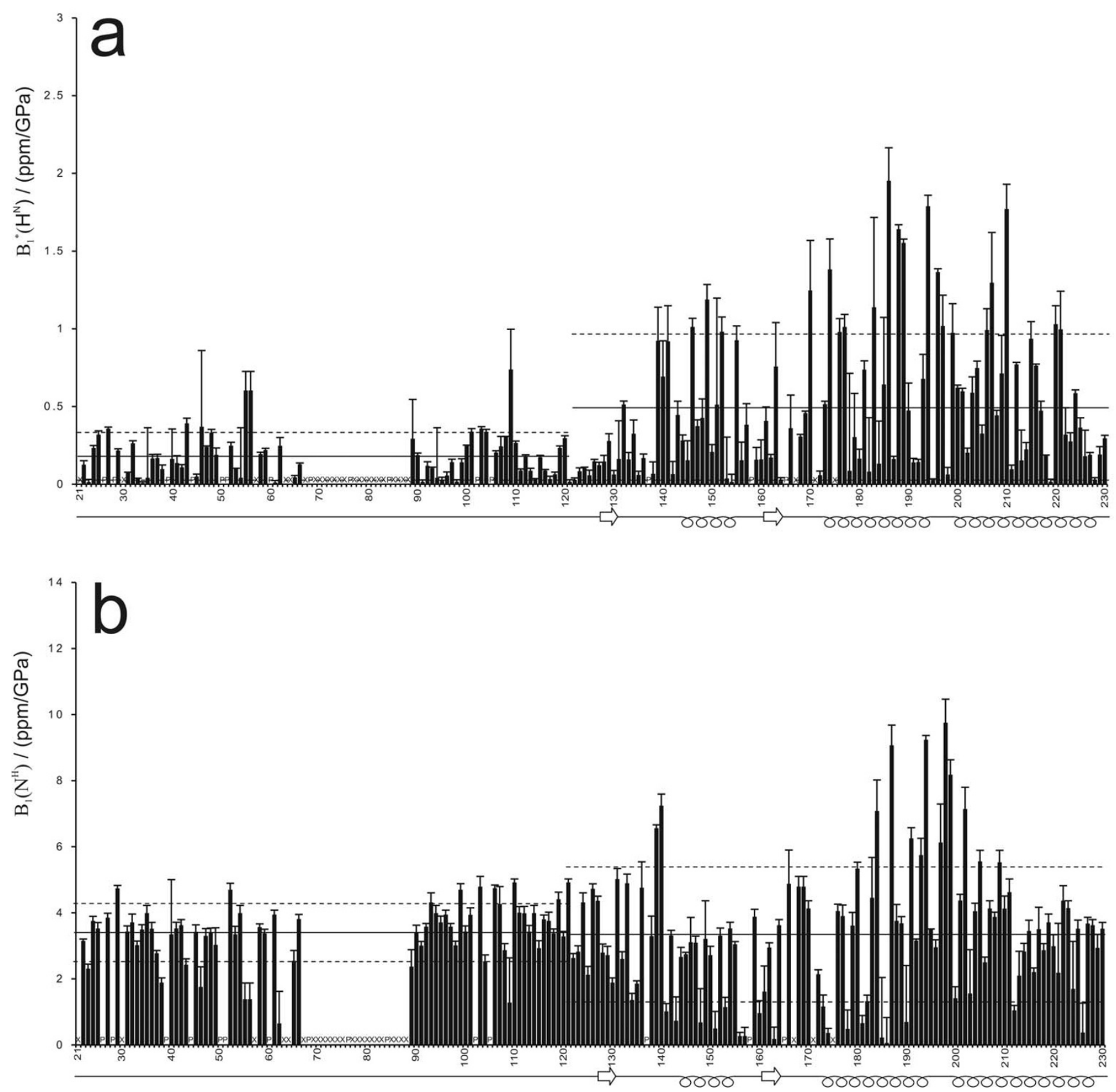

Figure I

First order pressure coefficients of the ${ }^{1} \mathrm{H}^{\mathrm{N}}$ and of the ${ }^{15} \mathrm{~N}^{\mathrm{H}}$ chemical shifts taken from the TROSY-HSQC spectra of huPrP(23230). Spectra were measured at $293 \mathrm{~K}$ at $600 \mathrm{MHz}$ proton frequency. The absolute values of the conformation dependent pressure coefficients $\left|\mathrm{B}_{I} *(\mathrm{H})\right|(\mathbf{a})$ for the ${ }^{1} \mathrm{H}^{\mathrm{N}}$ shifts and of the uncorrected pressure coefficient $\left|\mathrm{B}_{1}(\mathrm{~N})\right|(\mathbf{b})$ for the ${ }^{15} \mathrm{NH}^{\mathrm{H}}$ chemical shifts are plotted as function of the sequence position. The mean values of $\left|B_{I} *(H)\right|$ and $\left|B_{I}(N)\right|$ for the structured $C$-terminal and the unstructured $\mathrm{N}$-terminal part of the protein are shown as solid lines, the mean values plus one standard deviation as dashed lines. The secondary structure is symbolized by arrows ( $\beta$-strands) and lanyards ( $\alpha$-helices). P marks prolines, $X$ other residues that are not visible or not assigned in the TROSY spectra.

pressure-sensitive regions for both, ${ }^{1} \mathrm{H}^{\mathrm{N}}$ and ${ }^{15} \mathrm{~N}^{\mathrm{H}}$, overlap quite well but not completely. Almost the same residues are also identified by the second order coefficients. The same is true for the residues with a very small pressure response, namely 129, 130, 148, 156, 174, 178, 182, 186, 187, 190, 192, 212, 219 and $221\left(\left|B_{1}(N)\right|\right.$ smaller than 

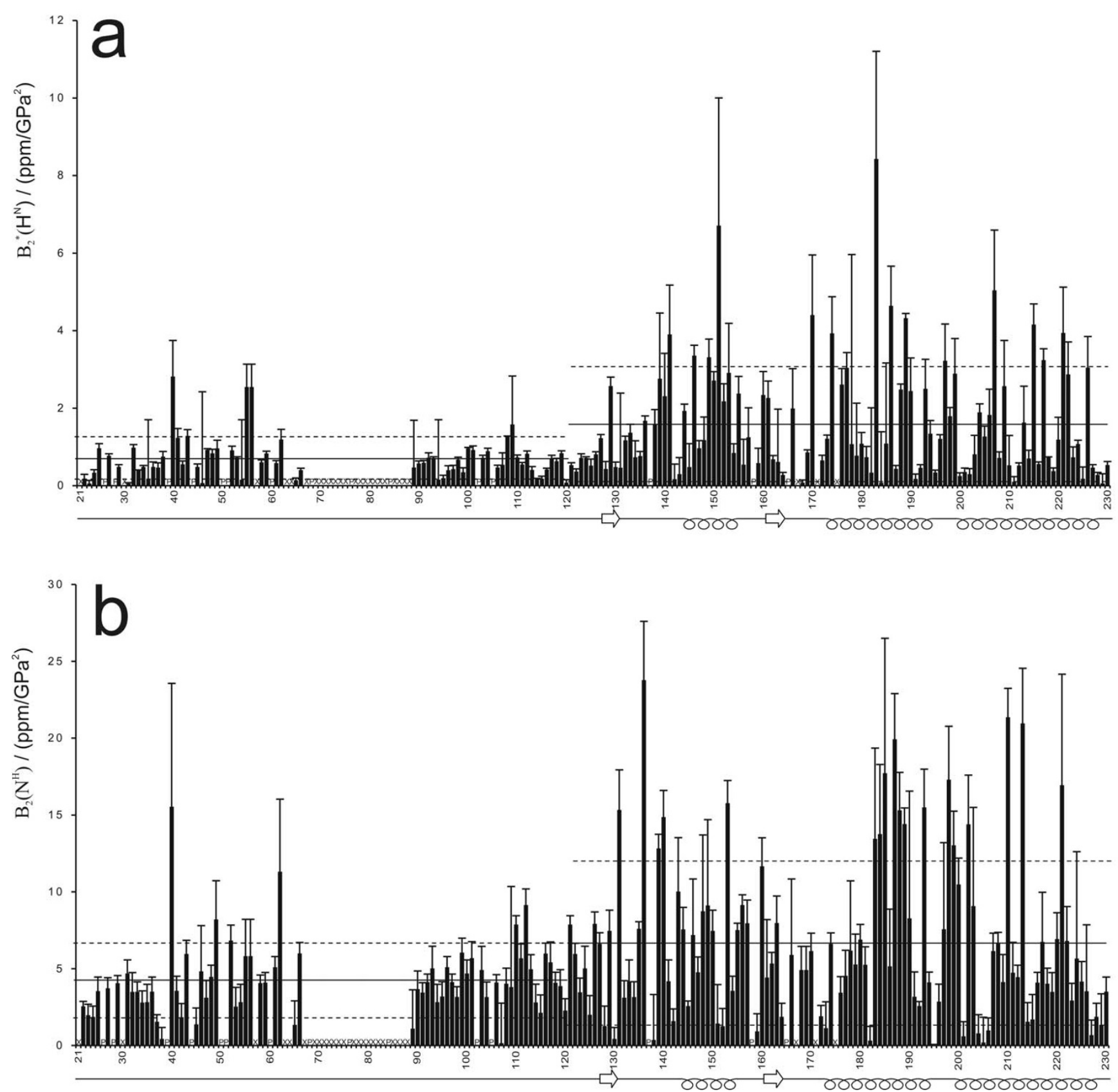

\section{Figure 2}

Second order pressure coefficients of the ${ }^{1} \mathrm{H}^{\mathrm{N}}$ and of the ${ }^{15} \mathrm{~N}^{\mathrm{H}}$ chemical shifts taken from the TROSY-HSQC spectra of huPrP(23-230). Spectra were measured at $293 \mathrm{~K}$ at $600 \mathrm{MHz}$ proton frequency. The absolute values of the conformation dependent pressure coefficients $\left|B_{2} *(H)\right|(a)$ for the ${ }^{I} H^{N}$ shifts and of the uncorrected pressure coefficient $\left|B_{2}(N)\right|(b)$ for the ${ }_{15} \mathrm{NH}^{\mathrm{H}}$ chemical shifts are plotted as function of the sequence position. The mean values of $\left|\mathrm{B}_{2} *(\mathrm{H})\right|$ and $\left|\mathrm{B}_{2}(\mathrm{~N})\right|$ for the structured $\mathrm{C}$-terminal and the unstructured $\mathrm{N}$-terminal part of the protein are shown as solid lines, the mean values plus one standard deviation as dashed lines. The secondary structure is symbolized by arrows ( $\beta$-strands) and lanyards ( $\alpha$-helices). $P$ marks prolines, $X$ other residues that are not visible or not assigned in the TROSY spectra.

the mean value minus one sigma) and $121,122,123,126$, $127,128,130,133,135,138,140,142,160,164,172$, $177,180,184,193,198,213,222,225,226,227,228$
$\left(\left|B_{1}^{*}(H)\right|\right.$ smaller than the mean value minus 0.75 sigma) in case of $h u \operatorname{PrP}(121-230)$. As has been stated above and has been quantified by the correlation analysis the pres- 

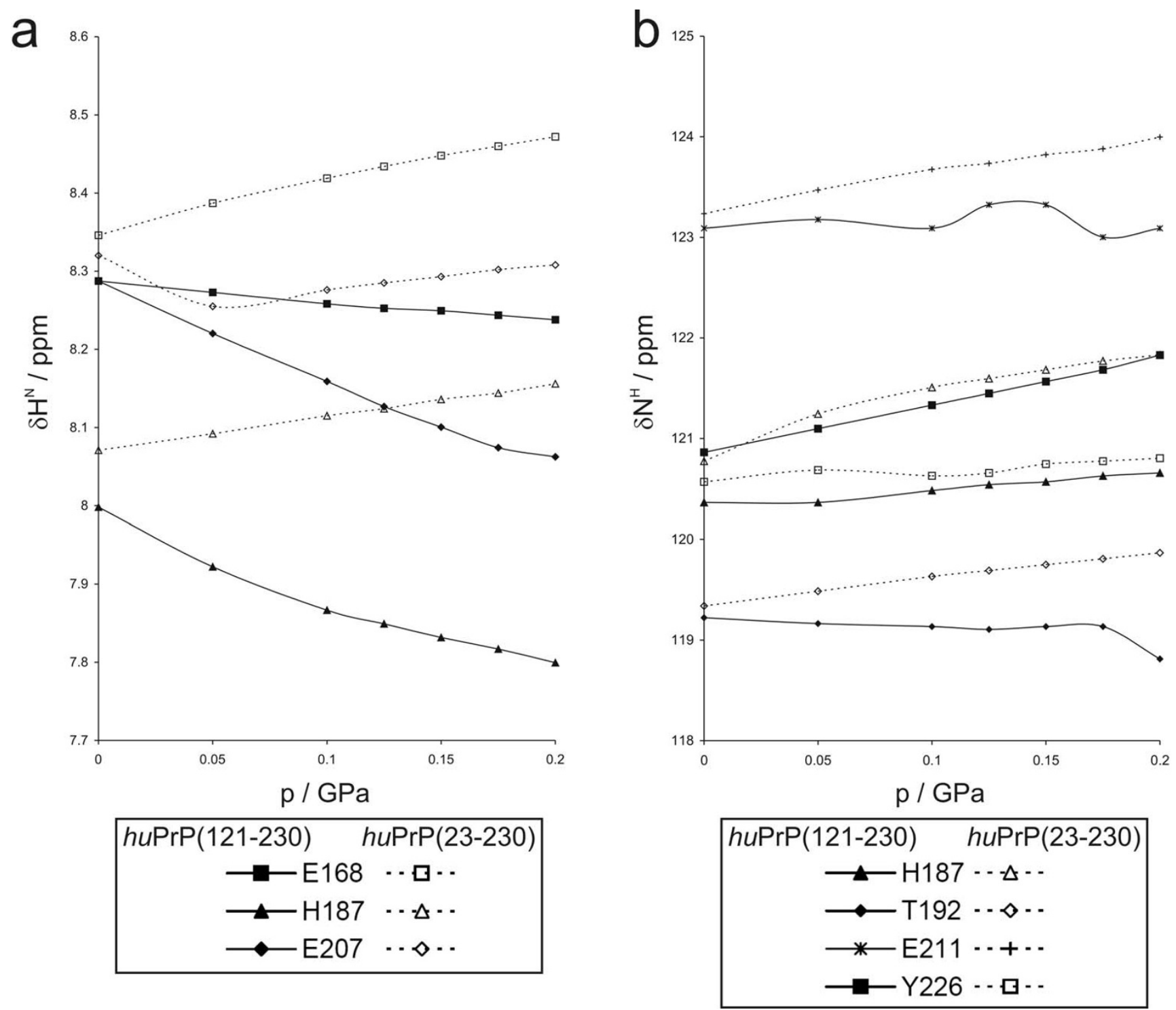

\section{Figure 3}

Differences in the pressure response in truncated and full length huPrP. The pressure dependences of the ${ }^{1 H}(\mathbf{a})$ and ${ }^{15} \mathrm{~N}$ chemical shifts $\delta(\mathbf{b})$ of selected amide groups are plotted for the truncated (solid lines) and the full-length $\operatorname{PrP}$ (dashed lines). Spectra were measured at $293 \mathrm{~K}$ at $600 \mathrm{MHz}$ proton frequency.

sure response of the amide nitrogen atoms of residues 121-230 of $h u \operatorname{PrP}(23-230)$ is very similar to that of $h u \operatorname{PrP}(121-230)$. In conclusion, $h u \operatorname{PrP}(121-230)$ is a good model for the study of pressure effects on the structured core of the whole protein.

The N-terminal part of the protein (amino acids 23 to 120 ) is assumed to be unstructured and thus should show only small pressure effects (Figs. 1 and 2). This is in general true, the mean first and second order pressure coefficients $\left|B_{1}{ }^{*}(H)\right|,\left|B_{1}(N)\right|,\left|B_{2}{ }^{*}(H)\right|$, and $\left|B_{2}(N)\right|$ are with $0.18 \mathrm{ppm} / \mathrm{GPa}, 3.37 \mathrm{ppm} / \mathrm{GPa}, 0.68 \mathrm{ppm} / \mathrm{GPa}^{2}$, and 4.20 $\mathrm{ppm} / \mathrm{GPa}^{2}$ significantly smaller than in the folded part of the protein. However, a number of residues show pressure coefficients that are above the average. Surprisingly, this is also true for the amide proton shifts, where the pressure coefficients of random coil peptides [36] were subtracted. Notably, K27, S43, G46, G55, G56, K101, S103, K104 and M109 show linear pressure coefficients that deviate significantly from the expectation. For the quadratic coefficients this applies to G40, S43, G55, G56, N108 and M109. If the N-terminus would be completely unstructured, only pressure coefficients in the magnitude of the random coil peptide values would be expected. 

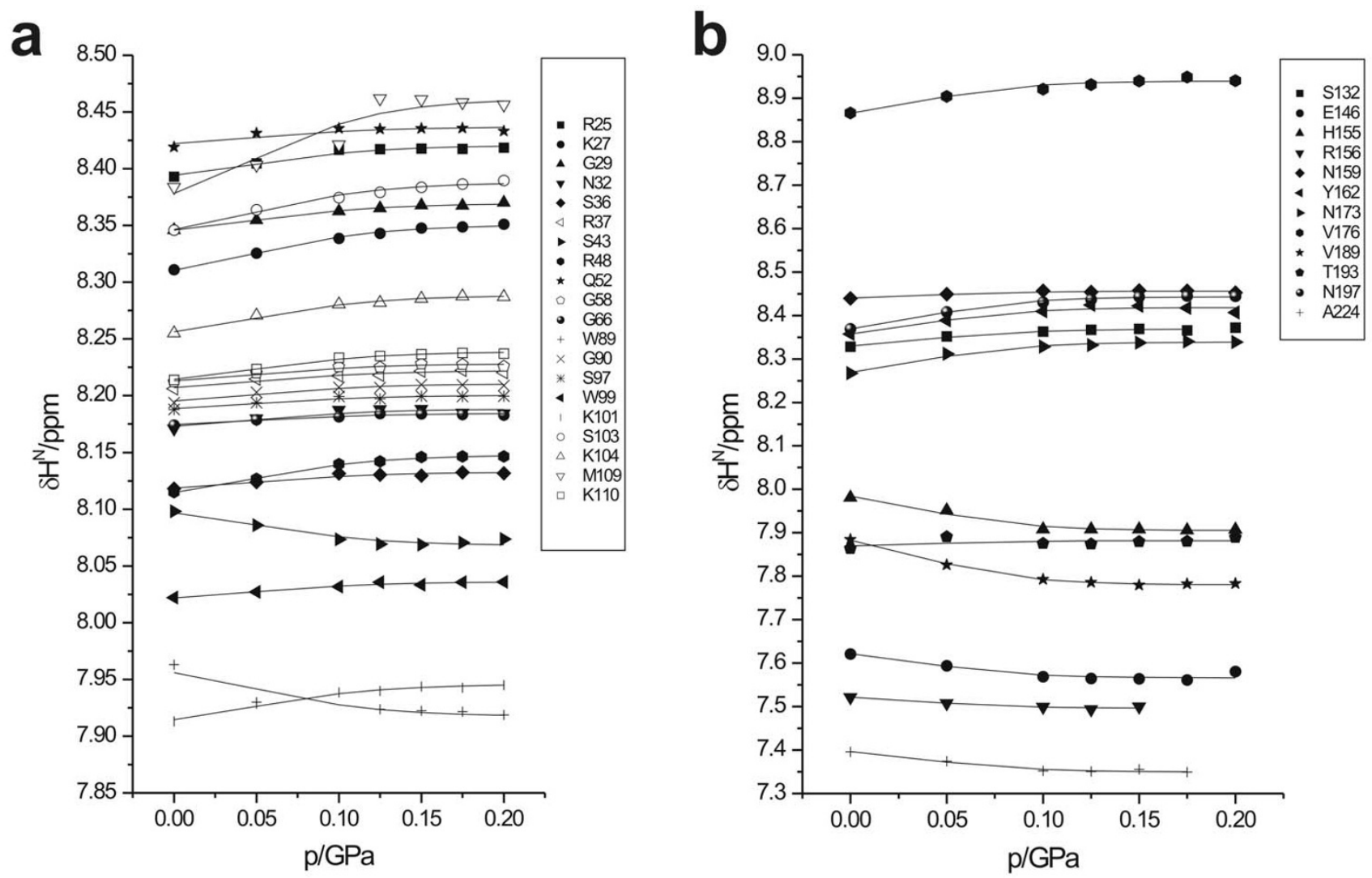

\section{Figure 4}

Pressure dependent population changes in fast exchange. The chemical shifts $\delta^{*} H^{N}$ of the amide protons taken from a set of TROSY-HSQC spectra measured at $293 \mathrm{~K}$ are plotted as function of pressure $\mathrm{p}$. The chemical shifts $\delta^{*} \mathrm{H}^{\mathrm{N}}$ were corrected by the known pressure response of random-coil peptides (see Methods). All residues with a clearly asymptotic pressure dependence of the chemical shifts are shown. The lines represent the fit of the data to equation (2).(a) Data from $\mathrm{N}$-terminal part of huPrP(23-230) and (b) from the C-terminal structured part of huPrP(12I-230).

\section{Pressure response of chemical shifts and related Gibbs free energies}

Some of the residues show strong non-linear pressure dependences of the chemical shifts together with an asymptotic behavior within the pressure range studied (Fig. 4) which would be typical for a two-state transition in fast exchange on the NMR-time scale. In this model, at ambient pressure two local conformational states $\mathrm{N}_{1}$ and $\mathrm{N}_{2}$ coexist that are sensed by the corresponding residues. At high pressure the local conformational equilibrium of the protein is completely shifted from the ground state to the low-lying excited state $\mathrm{N}_{2}$. The molar free energy $\left(\Delta G_{0}\right)$ for this local transition can be derived from the chemical shift change by equation (2) (see Methods). As already discussed above for removing unspecific pressure effects from specific conformation dependent effects, prior to the calculation of the Gibbs free energies $\Delta G_{0}$ the pressure- induced chemical shift change as determined for the random coil standard peptides [36] was subtracted from the measured chemical shift values. Since that was only possible for the proton shifts only these were evaluated quantitatively. However, qualitatively the pressure dependence of the nitrogen chemical shifts followed the same rules.

For the residues of the structured core ( $h u \operatorname{PrP}(121-230))$ one obtains $3.0 \pm 1.4 \mathrm{~kJ} / \mathrm{mol}$. The $\Delta G_{0}$ value for the pressure-induced transition of the $\mathrm{N}$-terminal residues of $h u \operatorname{PrP}(23-230)$ is $3.0 \pm 1.1 \mathrm{~kJ} / \mathrm{mol}$ (Table 1 ). At ambient pressure about $71 \%$ of the protein are in the highest populated native "ground state" conformation, whereas $29 \%$ are in the second "excited" native conformation which is favored by applying pressure. From the fast exchange condition, a lower limit for the exchange correlation rate $1 / \tau_{e}$ of $22 \mathrm{~s}^{-1}$ can be estimated for the $\mathrm{N}_{1}-\mathrm{N}_{2}$ transition. 
Table I: Gibbs free energies and specific volumes ${ }^{\mathbf{a}}$

\begin{tabular}{|c|c|c|c|c|c|}
\hline Domain & Transition & $K_{0}$ & $\Delta G_{0}\left[\mathbf{k J ~ ~ m o l ^ { - 1 } ]}\right.$ & $\Delta V_{0}\left[\mathrm{ml} \mathrm{mol}^{-1}\right]$ & $\Delta V_{0}\left[\mathrm{~nm}^{3}\right]$ \\
\hline \multicolumn{6}{|l|}{$h u \operatorname{PrP}(23-230)$} \\
\hline \multirow[t]{2}{*}{ amino acid $23-120$} & $N_{1}-N_{2}$ & 0.292 & $3.0 \pm 1.1$ & $-63 \pm 11$ & $-0.10 \pm 0.02$ \\
\hline & $N>1$ & n. d. & n. d. & n. d. & n. d. \\
\hline \multirow[t]{2}{*}{ amino acid $|2|-230$} & $\mathrm{~N}_{1} \rightarrow \mathrm{N}_{2}$ & 0.300 & $2.9 \pm 1.3$ & $-79 \pm 15$ & $-0.13 \pm 0.02$ \\
\hline & $N>1$ & n. d. & n. d. & n. d. & n. d. \\
\hline \multicolumn{6}{|l|}{ huPrP(I2|-230) } \\
\hline \multirow[t]{3}{*}{ amino acid $|2|-230$} & $N_{1}-N_{2}$ & 0.292 & $3.0 \pm 1.4$ & $-86 \pm 17$ & $-0.14 \pm 0.03$ \\
\hline & $N \triangleright I_{1}$ & 0.012 & $10.8 \pm 1.9$ & $-66 \pm 26$ & $-0.11 \pm 0.04$ \\
\hline & $\mathrm{N} \triangleright \mathrm{I}_{2}$ & 0.0005 & $18.6 \pm 2.9$ & $-125 \pm 32$ & $-0.21 \pm 0.05$ \\
\hline
\end{tabular}

a Data were measured at $293 \mathrm{~K}$ and represent the average of the residues in the corresponding domains. $K_{0}$ and $\Delta G_{0}$ are the values calculated for $293 \mathrm{~K}$ and $0.1 \mathrm{MPa}$.

\section{Pressure response of cross peak volumes and the related Gibbs free energies}

At $200 \mathrm{MPa}$ the amide proton resonances of residues Y128, G131, M134, R136, I139, F141, G142, S143, D144, Y150, R156, Q160, V161, Y163, N174, D178, I182, T199, E200, D202, V210, C214, I215, Q217 and E221 are not observable in case of $h u \operatorname{PrP}(121-230)$. Especially, the cross peak of Gly131 disappears already at $125 \mathrm{MPa}$, while residues Ile139, Phe141, Gln160, Val161, Tyr163 and Asp178 become undetectable at $150 \mathrm{MPa}$. These residues mainly cluster to the loop between the strand $\beta 1$ and helix $\alpha 1$, near helix $\alpha 3$ and close to the $\beta$-sheet. In case of $h u \operatorname{PrP}(23-230)$ qualitatively the same process can be observed for the core region, however, since in the longer construct the resolution is reduced and becomes worse with increasing pressure only the disappearance of residues Gly131, Ile139, Phe141, Arg156 and Asp178 can be reliably confirmed. The $\mathrm{N}$-terminal unstructured region displays a less pronounced chemical shift dependence and no significant volume change upon pressure (Fig. 5a). By releasing the pressure we observe the original spectra at ambient pressure again, thus the pressure-induced changes are completely reversible.

There are two possible explanations for this loss in intensity, increased loss of intensity during the INEPT-periods by increased average $T_{2}$-relaxation and/or a two site exchange which is slow on the NMR-time scale and where the second signal would be too weak to be observable [37]. The increased transverse relaxation rate could be due to an exchange broadening or an increased effective molecular size by protein aggregation. The last mechanism could also lead to a disappearance of the second signal in the slow exchange regime. Under fast exchange conditions the increased transverse relaxation time can also be estimated from the broadening of the signals by pressure. The observed increase in line width by a factor 1.2 to 2 is too small to account for the observed loss in signal intensities if fast exchange conditions would prevail.
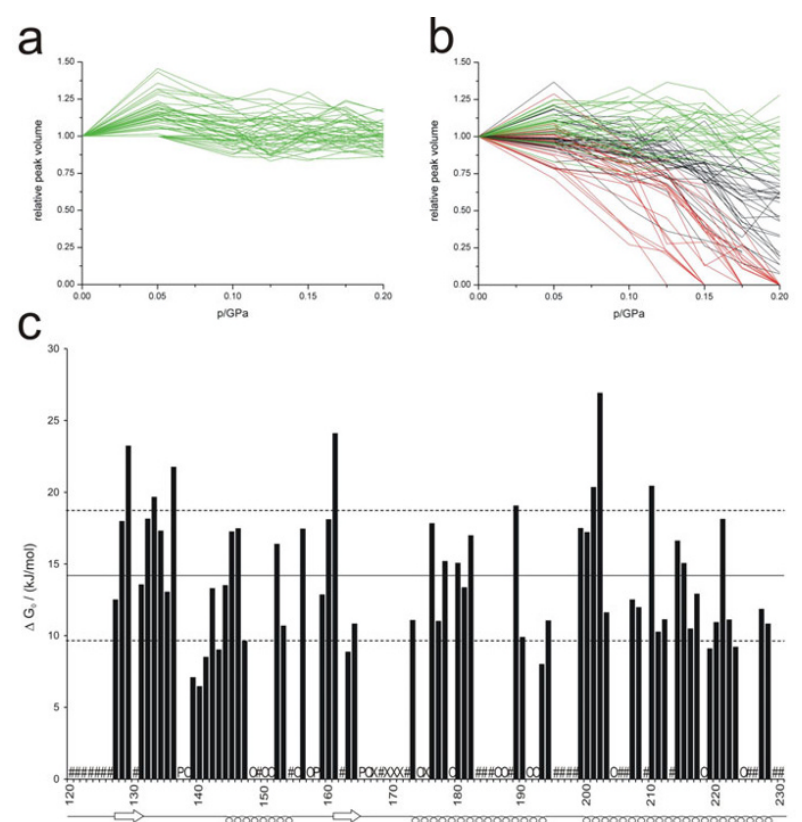

Figure 5

Pressure dependence of signal volumes in TROSY-HSQC spectra. The signal volumes are normalized to their volumes at ambient pressure and plotted as function of pressure. (a) Signal volumes from the $\mathrm{N}$-terminus (residues 23-120) and (b) from the structured core (residues I2I-230) are shown. Residues with no significant signal loss are highlighted green, disappearing signals are marked red. (c) Molar free energies at ambient pressure $\left(\Delta G_{0}\right)$ for the $N$ to I transition of huPrP(I2I-230) calculated for individual residues assuming a slow exchange model. The mean value of $\Delta G_{0}(14.2 \mathrm{~kJ} / \mathrm{mol})$ is shown as solid line, the mean value plus/minus one standard deviation as dashed lines. Residues without a significant change in the signal volume are marked with \#. O means, that the signal volume could not be determined due to heavy overlap of the peaks. $P$ marks prolines, $X$ other residues that are not visible or not assigned in the TROSY spectra. 
Using the approximations derived by Maurer et al. [37] a maximum intensity decrease by $20 \%$ could follow from that additional, pressure dependent line broadening. For most of the residues under consideration the intensity loss during the polarization transfer process is considerably smaller, thus pointing towards a slow exchange process with an intermediate conformation. A line broadening of the same magnitude as observed for the amide groups is also observed in 1D-spectra for resonances of nonexchangeable protons. As an example the high-field shifted methyl resonances of Leu125, Leu130, Ile139 and Ile182 are shown in Fig. 6. As seen in the TROSY spectra, in the 1D spectra a certain number of peaks shows no or only weak line broadening, too. The line broadening is not caused by a change of the viscosity of water with pressure, since at $293 \mathrm{~K}$ the water viscosity shows only weak pressure dependence up to pressures above $200 \mathrm{MPa}$. Actually the viscosity even decreases till $80 \mathrm{MPa}$ to about 98\% and displays a moderate increase with increasing pressure above that. At about $140 \mathrm{MPa}$ it reaches its original value again [38]. Thus, the origin of the line broadening might be due to conformational heterogeneity and/or exchange.

Assuming two site model under slow exchange conditions the pressure induced changes of volumes and thus of the corresponding populations can be used to calculate a molar free energy $\left(\Delta G_{0}\right)$ for every single amino acid residue in the polypeptide chain. The equilibrium constant $K$ between the native state and the pressure populated intermediate can then be derived from the ratio of the peak volumes (see Methods). Fig. 5c shows the molar free energies at ambient pressure obtained from a fit of the data as a function of the primary structure of $h u \operatorname{PrP}(121-230)$. The secondary structure elements are indicated at the bottom. Due to signal overlap it was not possible to determine exact values for the cross peak intensities of every residue which leads to gaps in the residue specific determination of the pressure stability (marked with "O"). Residues which show no significant change of the signal intensity are marked with "\#". The average for the molar free energies $\Delta G_{0}$ and their standard deviations are indicated in Fig. $5 \mathrm{c}$ by a solid and two broken lines. The mean of $\Delta G_{0}$ is $14.2 \mathrm{~kJ} / \mathrm{mol}$ with a standard deviation of $4.5 \mathrm{~kJ} /$ mol. The distribution of free energies is depicted in Fig. 7a showing that the obtained energy distribution is clearly divided into two groups. Fig. 7b shows peak volumes and the $\Delta G$ fit of typical residues of both groups. In Fig. 8 the two groups are mapped on the structure of $h u \operatorname{PrP}(121-$ 230). Group one encompasses 33 residues and has a $\Delta G_{0}$ of $10.8 \pm 1.9 \mathrm{~kJ} / \mathrm{mol}$, the mean $\Delta G_{0}$ of the 25 residues of group two is $18.6 \pm 2.9 \mathrm{~kJ} / \mathrm{mol}$.

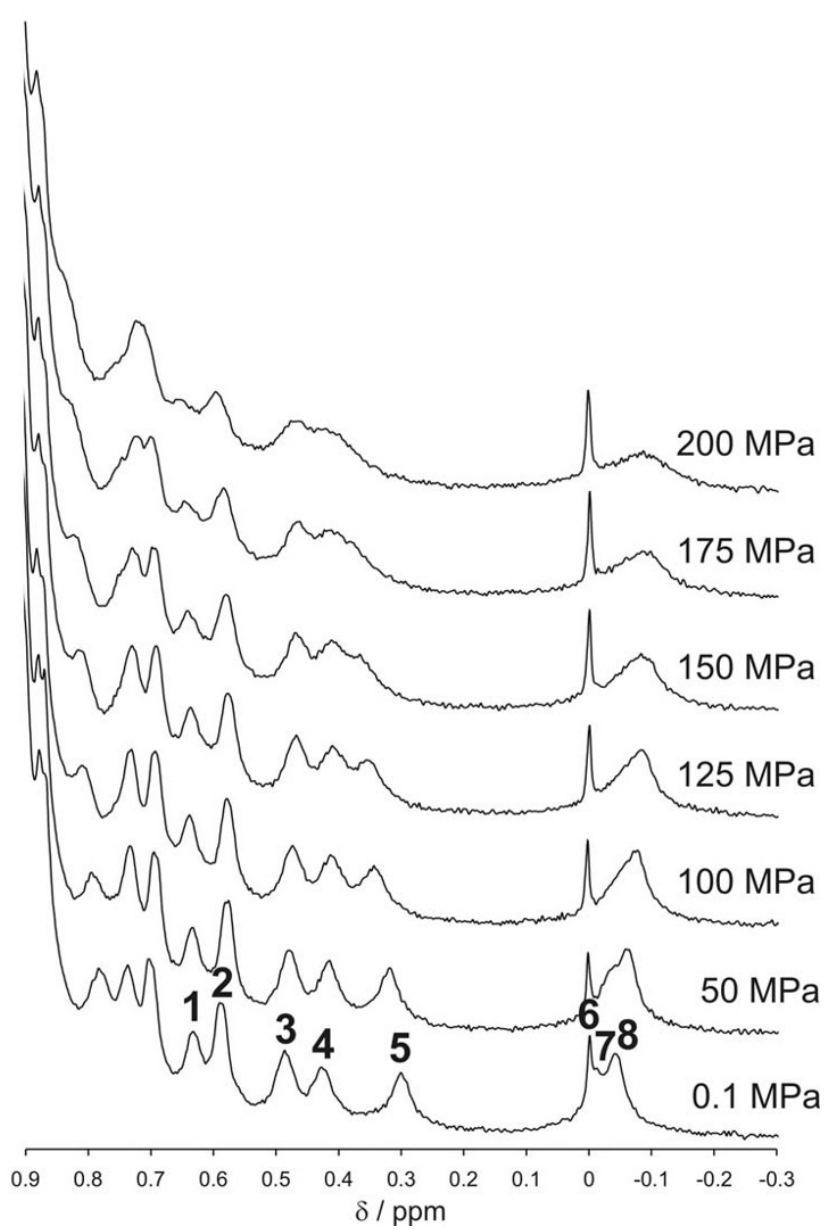

Figure 6

IH NMR spectra of huPrP(23-230) recorded at $293 \mathrm{~K}, \mathrm{pH}$ 4.8 and at different pressures. Resonances of selected protons are labeled: (I) Leu I $30 \mathrm{H}^{\delta 2}$ (2) Leu $25 \mathrm{H}^{\delta 2}$ (3) Ile I 39 $\mathrm{H}^{\delta I}$ (4) lle $182 \mathrm{H}^{\delta 1}(5)$ lle $182 \mathrm{H}^{\gamma 2}$ (6) DSS (internal reference) (7) Leu $30 \mathrm{H}^{\delta 1}$ (8) Ilel $39 \mathrm{H}^{\gamma 2}$.

\section{Characterization of the folding intermediates}

The pressure response of $h u \operatorname{PrP}$ consists of three different effects: [1] Small linear chemical shift changes corresponding to small first-order pressure coefficients, [2] Non-linear chemical shift changes which show for some residues a typical asymptotic behavior as it would be expected for a fast exchange between slightly differing conformations, and [3] a loss of signal volumes which occurs for the majority of the amino acid residues. A thorough analysis shows the appearance of at least two different conformational transitions between the ground state $\mathrm{N}_{1}$, the low-lying excited state $\mathrm{N}_{2}$ and the intermediate states $[25,28,39]$. At ambient pressure the chemical shift data allow us to postulate the states $\mathrm{N}_{1}$ and $\mathrm{N}_{2}$, and the analysis of the signal volume loss induced by pressure indicates additional intermediate states $\mathrm{I}_{1}$ and $\mathrm{I}_{2}$. Strong pressure responses are often associated with the existence 

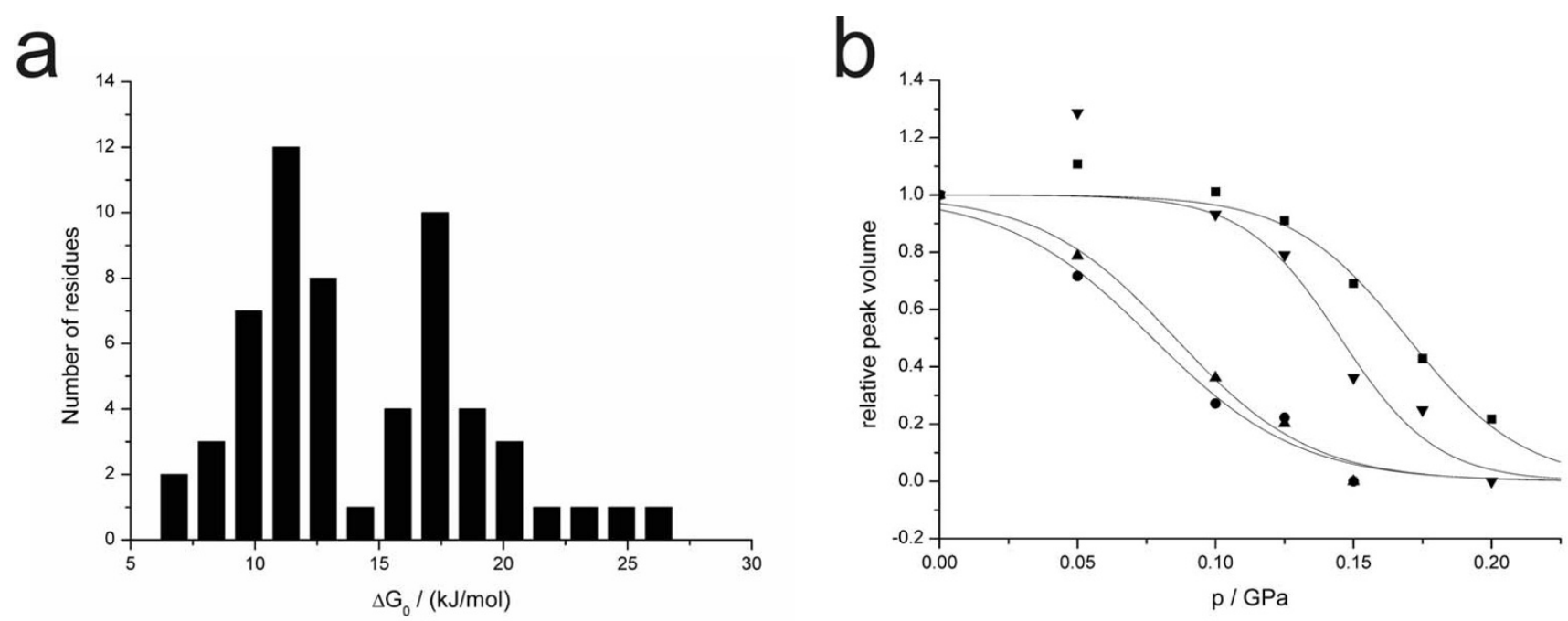

Figure 7

(a) Distribution of residue specific $\Delta G_{0}$ at $293 \mathrm{~K}$ for the transition from states $\mathrm{N}_{1}$ and $\mathrm{N}_{2}$ or $\mathrm{N}_{2}$ only to state $\mathrm{I}_{1}$ and $\mathrm{I}_{2}$ obtained from the pressure induced volume changes. (b) Pressure dependence of signal volumes in TROSY-HSQC spectra at $293 \mathrm{~K}$ with fit of the data by eq. 5. Typical residues of $\mathrm{I}_{\mathrm{I}}(\mathrm{II} 39 \mathrm{O}, \mathrm{FI} 4 \mathrm{I} \mathbf{\Delta})$ and $\mathrm{I}_{2}(\mathrm{Al} 33 \mathbf{\square}, \mathrm{V} 2 \mathrm{IO} \nabla)$ are shown.

of packing defects, or cavities in the direct neighborhood. The cavities calculated from the PDB deposited structure (code 1QM2) are also shown in Fig. 8. The found cavity at this position is surrounded by acidic side chains thus leading to a hydrophilic pore. Close to helices $\alpha 2$ and $\alpha 3$ similar packing defects are also seen.

The pressure dependent energy landscape of the human prion protein is shown in Fig. 9 schematically. At ambient pressure two native states $\mathrm{N}_{1}$ and $\mathrm{N}_{2}$ as well as the energetic unfavorable excited intermediate states $\mathrm{I}_{1}$ and $\mathrm{I}_{2}$ are visible. With increasing pressure the energy profile changes. At the onset of pressure $\mathrm{N}_{2}$ becomes the energetically lowest and therefore highest populated conformation. At very high pressures the intermediate conformations $\mathrm{I}_{1}$ and $\mathrm{I}_{2}$ are strongly favored.

\section{Discussion}

A key point of the prion only hypothesis has been finally proven by different groups $[8,14,40]$ showing that it is possible to produce in vitro conformations of the prion protein which can confer infectivity. This conformation is generated by a seeding process which is so potent, that even sequence-based barriers that prevent cross-seeding between prion proteins from different species can be bypassed in vitro. Such a template-induced adaptation process is leading then to the emergence of new strains of prion fibrils $[12,41,42]$. It is obvious, that the pathway of prion protein assembly into amyloid and possibly into infectious protein implies a whole variety of subconformations and is extremely complex [43].

The investigation of multiple misfolding pathways of the prion protein is indispensable to pinpoint down the regions involved in the protein conversion from $\mathrm{PrPC}^{\mathrm{C}}$ to PrPSc. Folding or unfolding intermediates are usually created by use of denaturing agents. An elegant alternative to this is the application of hydrostatic pressure which allows to stabilize and study intermediate forms in the folding pathway of PrP [33]. Pressure can also induce scrapie-like prion protein misfolding and amyloid fibril formation as has been shown by Lange and co-workers [30]. Torrent et al. [30] showed an irreversible aggregation of Syrian hamster prion protein ShaPrP(90-231) above $450 \mathrm{MPa}$, and incubation of $\operatorname{ShaPrP}(90-231)$ at $600 \mathrm{MPa}$ overnight led to the formation of amyloid fibrils, whereas pressures up to $200 \mathrm{MPa}$ led to reversible effects and recovery of the original structure after pressure release [29]. NMR spectroscopy is the only generally applicable method to monitor pressure-induced structural changes at the atomic level in solution. Our current setup allows us to monitor such changes between 0.1 and $200 \mathrm{MPa}$. Here all pressure-induced structural changes were reversible as also be observed by NMR in the hamster prion protein [34]. However, a detailed comparison at an atom to atom level with our data is not possible since Kuwata et al. used a less sophisticated evaluation method, especially in that study it was not investigated if the native and intermediate 
a
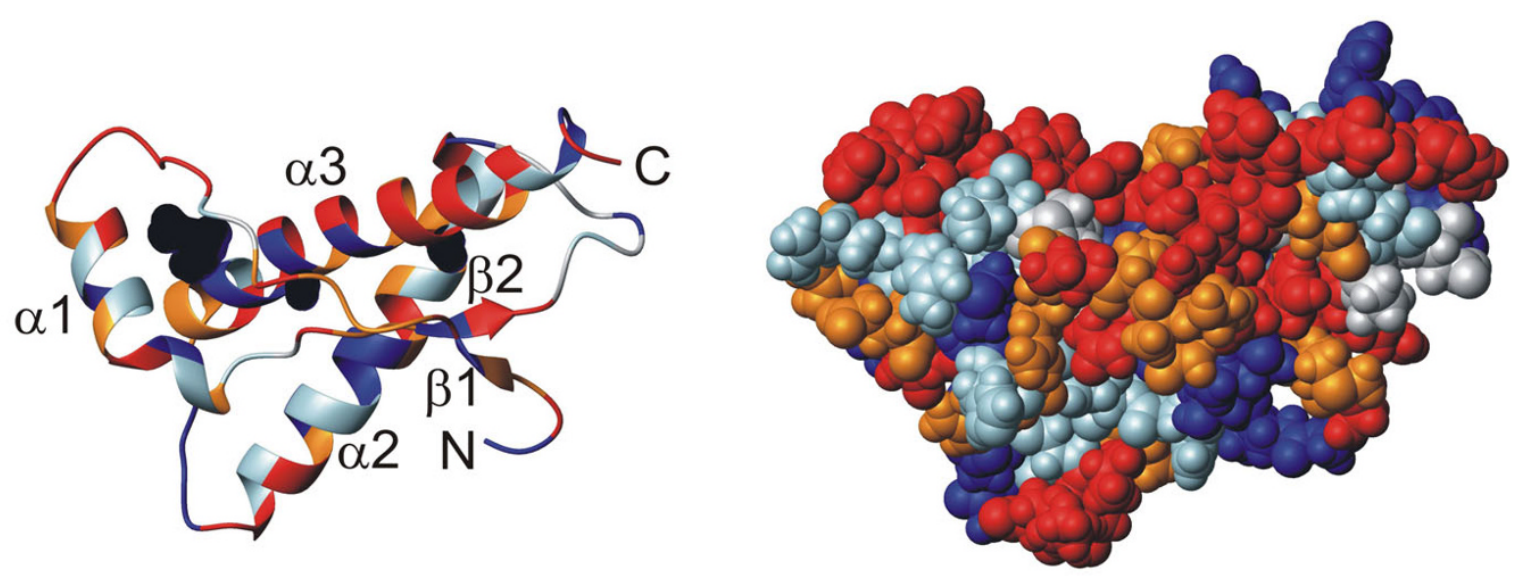

b
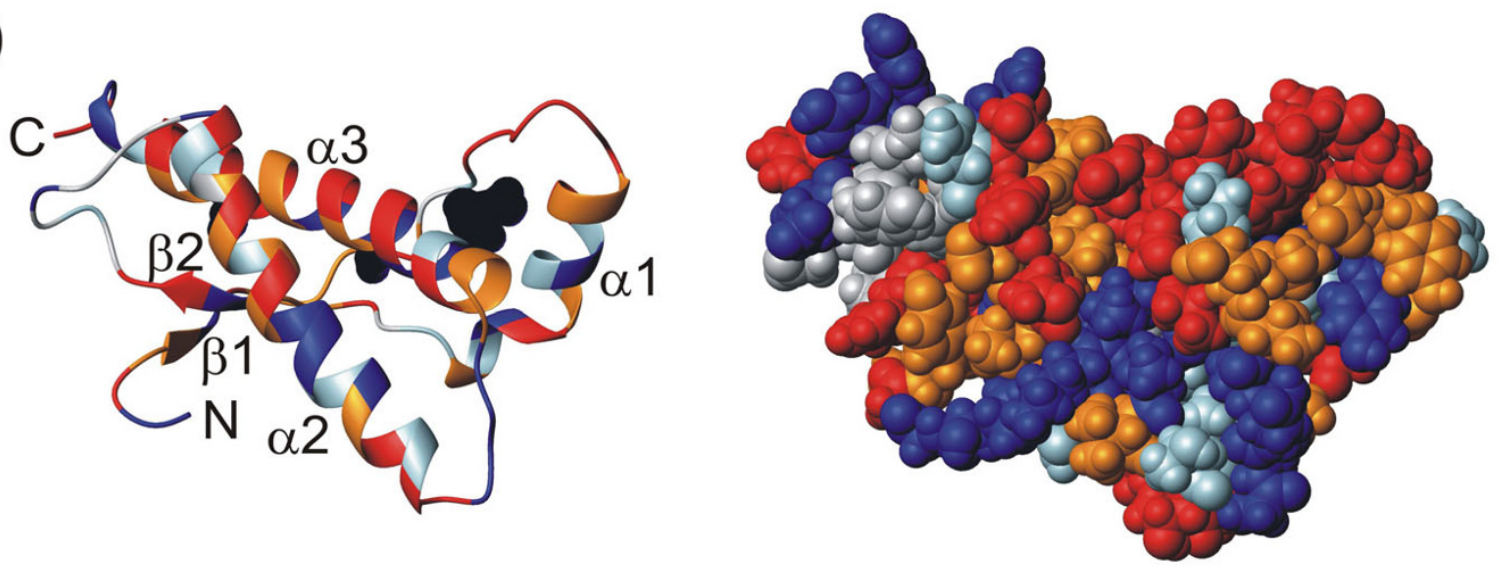

C
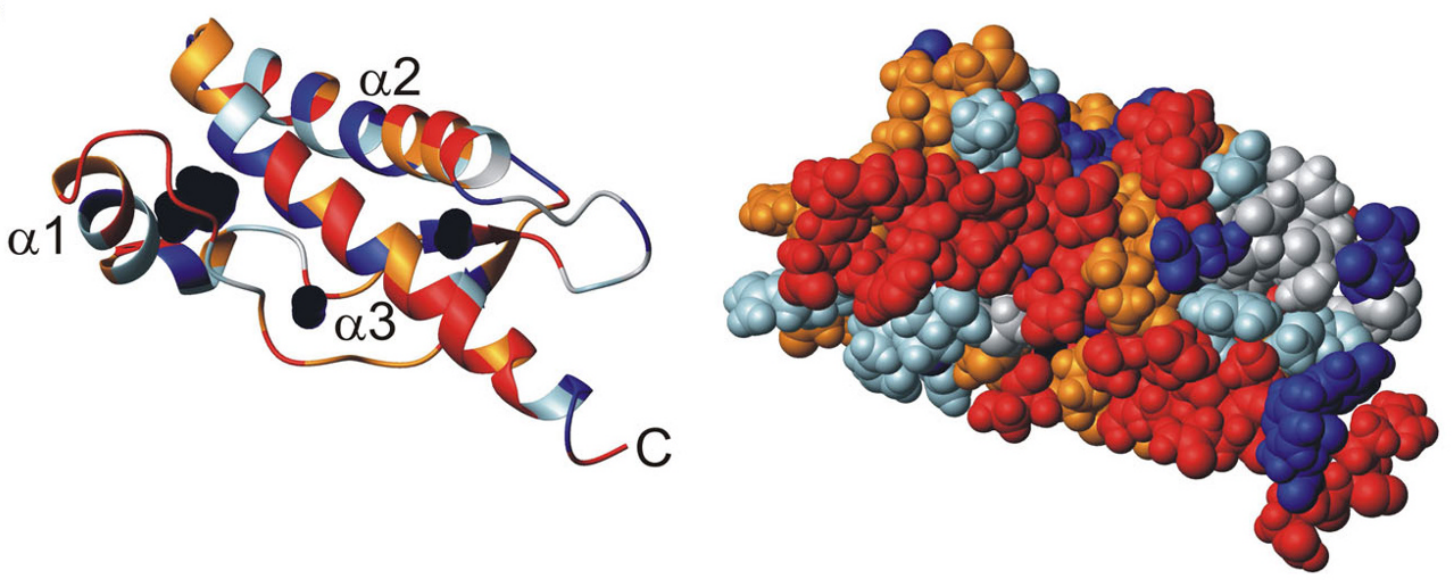

Figure 8

Pressure effects on huPrP(I2I-230). (a) Ribbon and CPK representations of the NMR structure of huPrP(I2I-230) (taken from PDB IQM2) with molecular cavities added (dark spheres) defined by a probe radius of $0.12 \mathrm{~nm}$. Residues showing no significant changes of the cross peak volumes are colored dark blue. Residues associated with $\Delta G_{0}$ values characteristic for the $N$ $\rightarrow$ I transition from group one (lower $\Delta G_{0}$ ) are depicted in red, from group two (higher $\Delta G_{0}$ ) orange. Regions where the signal volume could not be determined are colored light blue, residues not visible or assigned grey. (b) Same as (a) rotated by $180^{\circ}$ around the $y$-axis. (c) Same as (a) rotated by $90^{\circ}$ around the $x$-axis. Figure was prepared using MOLMOL [60]. 


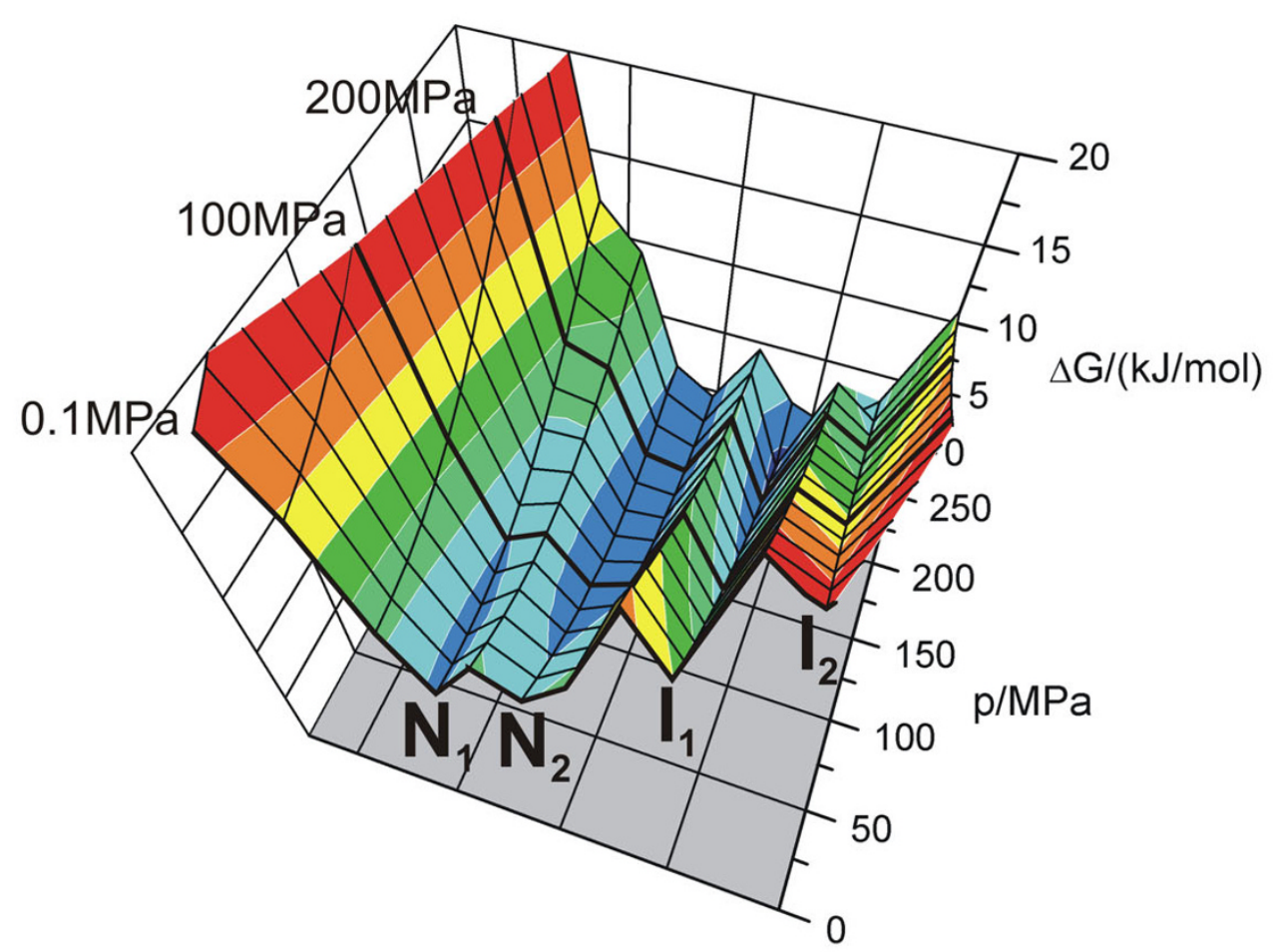

\section{Figure 9}

Schematic view of the free energy landscape of the human prion protein as a function of pressure. The molar free energy differences $\Delta G_{i}=G_{i}(P)-G_{N}(P)$ of the four main conformations $N_{1}, N_{2}$ and $I_{1}$ and $I_{2}$ are depicted as function of the pressure $P$ at constant temperature $T$ of $293 \mathrm{~K}$. In this representation as ground state $N$ the state $N_{1}$ was assumed (but see discussion). Note that the abscissa represents a generalized coordinate in the conformational space that only schematically depicts the conformational states.

state can be differentiated in substates with different free energies.

\section{Conformational states in proteins detected by variation of pressure}

Application of equations (2) to (5) allows the calculation of individual $\Delta G_{0}$ and $\Delta V$ values for all atoms in the molecule. When more than one parameter can be used as in our case the chemical shift change and the peak volume change more than one $\Delta G_{0}$ and $\Delta V$ value can be calculated for the structural transition observed by a single amide group in the protein. The question arises what the physical meaning of these values may be. In principle, $\Delta G_{0}$ and $\Delta V$ are global quantities that describe the difference of the Gibbs free energies and partial volumes of a state $\mathrm{X}_{\mathrm{i}}$ to an arbitrary state $X_{1}$ of the system. Since the number of pos- sible states of the system (that is the number of conformational states of the protein and the solvent molecules) is infinite one has to restrict to a smaller number of global states for obtaining meaningful results. In general one can separate the states of the bulk water from the rest of the system. Since pressure influences strongly the water shell close to the protein the effects on the shell and the protein conformation itself are difficult to separate.

Our analysis of $\mathrm{N}$ amide cross peak volumes and $2 \mathrm{~N}$ pressure induced ${ }^{1} \mathrm{H}$ and ${ }^{15} \mathrm{~N}$ chemical shift changes gives us information about $6 \mathrm{~N}$ different conformational states when the individual parameters follow a two-site exchange model. In case of multiple site exchange even more (sub)states would be expected. The primary evaluation of our shift and volume changes is done in this way. 
The same has been done by Kuwata et al. for the hamster prion protein but only volume changes were taken into account [34].

However, the structural substates in a protein-water system are usually coupled; the obtained atom specific $\Delta G_{0}$ and $\Delta V$ values are in general not to be interpreted locally since large contributions are due to structural differences of other parts of the molecule compared to the ground state (or the set of closely spaced low-energy states). As a further complication the calculation of the differences as done here must not necessarily refer to the same ground state.

After correction for unspecific "random coil" pressure induced shifts, we can group the $\Delta G_{0}$ and $\Delta V$ values in four main classes. This means in a minimal description of the system the substates $\mathrm{X}_{\mathrm{i}}$ are reduced to the combination of two "native" states $\mathrm{N}_{1}$ and $\mathrm{N}_{2}$ and two "intermediate" states $I_{1}$ and $I_{2}$. These states are primarily defined in the data evaluation as localized structural states and no information is available about the structural states of not directly considered other parts of the protein. Especially, in the data evaluation of the signal volume changes defining the intermediate states a localized native structural state has to be assumed. Since for some of the residues undergoing volume changes also shift changes corresponding to the $\mathrm{N}_{1}$ to $\mathrm{N}_{2}$ transition are observed, it seems plausible to assume that this transition is independent of the intermediate states and occurs in the whole protein. The calculated $\Delta G_{0}$ values then would refer to a state $N$ where the other parts of the molecules are in the structural state $\mathrm{N}_{1}$ or $\mathrm{N}_{2}$. The simplest picture would assume an ordered reaction scheme of conformational states $\mathrm{S}$.

$\mathrm{N}_{1} \leftrightarrows \mathrm{N}_{2} \leftrightarrows \mathrm{I}_{1} \leftrightarrows \mathrm{I}_{2}$

The quality of the data does not allow distinguishing between this model and more complicated possible models. The corresponding energy surface has been depicted schematically in Fig. 9. The abscissa here is a generalized arbitrary coordinate which represents the structural states of the proteins only schematically.

Since the data can be explained sufficiently well with four states only, we restrict in the following discussion on the existence of these four states. However, we cannot exclude the existence of additional structural states with indistinguishable free energies. The pressure dependences of the chemical shifts indicate the existence of a second native conformation of $h u \operatorname{PrP}$, which is favored under high pressure and is in fast conformational exchange with the "ground state". At ambient pressure $71 \%$ of the protein is in the main native state $\mathrm{N}_{1}$ and $29 \%$ are in the "excited" native conformation $\mathrm{N}_{2}$. The low energy difference $\left(\Delta G_{0}=\right.$
$3.0 \mathrm{~kJ} / \mathrm{mol}$ ) and the relatively small chemical shift differences between $\mathrm{N}_{1}$ and $\mathrm{N}_{2}$ implies, that only slight structural changes occur in the $\mathrm{N}_{1} \leftrightarrow \mathrm{N}_{2}$ transition. The state $\mathrm{I}_{1}$ and $\mathrm{I}_{2}$ are derived from the analysis of the volume changes of those resonances that are too broad to be observable in one of the states I. At ambient pressures only less than 1\% exists in $\mathrm{I}_{1}$ or $\mathrm{I}_{2}$. At $200 \mathrm{MPa}$ most of the protein is in state $\mathrm{I}_{1}$ or $\mathrm{I}_{2}$.

\section{Structural changes under high pressure}

The N-terminal region of $h u \operatorname{PrP}(23-230)$ is known to show no well-defined three-dimensional structure at the used buffer conditions. An analysis of the chemical shifts corrected for neighbor effects [44] indicates no welldefined regions where secondary structure is induced by pressure. Nevertheless, the complete $\mathrm{N}$-terminus has a tendency towards positive chemical shift values.

After subtracting the random-coil pressure coefficients within the limits of error vanishing first and second order pressure coefficients are expected for those parts of the structure that are in a random-coil conformation. Unfortunately, random-coil values do only exist for protons [36] but not for ${ }^{15} \mathrm{~N}$. Therefore, only the proton shifts can be interpreted in detail. In the presumably unstructured part (amino acids 23 to 120) the expectation values of $B_{1}{ }^{*}$ and $B_{2}{ }^{*}$ are with $0.11 \mathrm{ppm} / \mathrm{GPa}$ and $0.68 \mathrm{ppm} / \mathrm{GPa}^{2}$ close to zero (see Results). Most interestingly, the range of amino acids 90 to 170 where two-dimensional electron crystallography and molecular dynamics simulations $[45,46]$ predict $\beta$-sheet formation after polymerization displays a high variety of pressure sensitivity. The strands $\beta 1$ and $\beta 2$ seem to be very insensitive to the application of high pressure while the loop and the helix $\alpha 1$ in between these two strands exhibit some of the most pronounced changes in structure we observed by applying high pressure.

As indicated by the pressure induced chemical shift changes there are two native conformations $\mathrm{N}_{1}$ and $\mathrm{N}_{2}$ in fast conformational exchange, which coexist even at ambient pressure. The relatively small difference of the molar free enthalpies of both states as well as the rather small chemical shift changes indicate, that the $N_{1} \leftrightarrow N_{2}$ transition is only associated with a small structural rearrangement. Especially the very small chemical shift differences show that $\mathrm{N}_{1}$ and $\mathrm{N}_{2}$ adopt very similar structures. Unfortunately, a complete structural characterization of $\mathrm{N}_{2}$ cannot be performed by the available data.

The pressure dependent reduction of cross peak volumes in the TROSY-HSQC-spectra was associated with the $\mathrm{N} \leftrightarrow$ I transition. They can be due to increased $\mathrm{T}_{2}$-losses during the INEPT polarization transfer periods and/or a slow exchange process where the resonances of state I are 
broadened beyond detection [37]. In principle mainly two mechanisms can be responsible for an increased $T_{2}$, an increase of the rotational correlation time by proteinprotein interaction and exchange broadening. In onedimensional proton NMR spectra we observe a nearly general line broadening of approximately a factor two which could indicate a formation of dimers at higher pressure. In the TROSY-HSQC spectra also an additional line broadening with pressure is observed which varies locally but is clearly smaller than the factor of two. Additional line broadenings in the TROSY-spectra are mainly associated with chemical exchange processes. The observed increase of the transverse relaxation rates cannot explain the observed reduction of cross peak volumes as the only factor (see Results). Therefore, as additional factor a reduction of the peak volume by a slow exchange process is required as it has been done also for the hamster prion protein by Kuwata et al. [34]. In the absence of exchange broadening the cross peak volume change with pressure can be described by equations (4) and (5). In the presence of a moderate additional exchange these equations still provide a good approximation but the presence of exchange broadening would lead to too large estimates of the apparent $\Delta G_{0}$ values.

Within the limits of error the cross peak volume changes can be associated with two folding intermediates. In the folded core of the prion protein the region around positions Ile139, His140, and Phe141 shows rather low $\Delta G_{0}$ values that may indicate a larger exchange contribution. This may be interpreted as a premature local melting which correlates with a packing defect in this region (Fig. 8). A non-perfect stacking of side-chain and main-chain atoms leads to a less restricted peptide main chain in this area allowing a high degree of conformational freedom and thus conformational variability/heterogeneity. As pointed out by Pratt and co-workers [47] and has been observed experimentally by high-pressure NMR spectroscopy on RalGDS by us [25], pressure-induced unfolding is caused by the penetration of water into the hydrophobic core due to the dissociation of electrostatic bonds and solvation of hydrophobic residues. The sidechain resonance of the Ile139 methyl proton exhibits the most pronounced up field shift observed in the human prion protein indicating a strong interaction with the hydrophobic core of this protein.

Single low $\Delta G_{0}$ values are also found in the helical region encompassing $\alpha 2$ and $\alpha 3$ which is in agreement with the finding that helices are more prone to pressure than extended structures like $\beta$-strands. In a similar study Kuwata et al. [34] investigated in a high-pressure NMR study the Syrian hamster ShaPrP(90-231). They found the most pronounced effects in the helical region encompassing the helices $\alpha 2$ and $\alpha 3$ implying a complete unfolding of these two helices in a slow exchange process. In addition, our data show the occurrence of a pressure-stabilized "excited" state $\mathrm{N}_{2}$. The existence of that state was not taken into account in their data analysis. Subsequently we find a slow exchange process to two intermediate conformations, which are characterized by a melting of the region around Ile139-Phe141 and a partial melting of the helical region encompassing $\alpha 2$ and $\alpha 3$. Our data suggest a dual mechanism for the structural changes under pressure at least in the human prion protein. Especially the observation in intermediate $\mathrm{I}_{2}$ that the most stable region of the human prion protein is localized in the region of the two helices where the disulfide bridge is located corresponds very well with the hydrogen protection measurements by other groups $[48,49]$.

Vanik et al. [16] adopted the Y145 Stop variant for in vitro specific seeding of amyloid fibrils. In particular, they found that mouse or hamster PrP-specific amino acid substitutions at position 138 and 139 are sufficient to change essential amyloidogenic properties of $h u \operatorname{PrP}(23-144)$, with the mutant proteins adopting seeding specificities of PrP corresponding to different species. Vice versa, M138I/ M139I ShaPrP(23-144) adopted the properties of human $\operatorname{PrP}(23-144)$ [16]. Our results show that the importance of individual amino acids in PrP as determinants of the species barriers are due to their local conformational variability which can be highlighted by applying high pressure and monitored on an atomic scale through NMR spectroscopy. Especially, local clusters of very low stability found in our experiments are prone to change their conformation upon interaction with the infectious conformer PrPsc. Indeed, permissible first entry-points of the scrapie isomer need a certain degree of local conformational freedom to initiate the refolding of the cellular isomer to an infectious one. Thus, the species and transmission barrier is conserved through the differences in the conformational freedom of local areas in the protein structure which can vary substantially with differing solution conditions necessary for the proteolytic degradation of proteins in the cell.

\section{Structural states of $\mathrm{N}$-terminal parts of the huPrP}

The N-terminal part of $h u \operatorname{PrP}(23-230)$ exhibits regions with chemical shift responses that are not typical for random-coil peptides. Their first and/or second order pressure coefficients deviate significantly from the average (by more than a standard deviation). This is best visible for the proton shift coefficients since they could be corrected by subtracting the published random-coil values [36]. One can define four regions where at least one of the coefficients deviates significantly from the average, namely region A encompassing K27, region B encompassing G40, S43 and G46, region C encompassing G55 and G56 and region D with K101, S103, K104, N108 and M109. The 
data indicate that these regions have a non-random population of structural states that coexist in solution and show a characteristic change of populations with pressure. Region $\mathrm{C}$ is located within the three octapeptide repeats which are known to adopt a defined structure upon binding of copper [35]. Unfortunately, the amino acids of the three octapeptide repeats could not be resolved individually in the spectra. They seem to have a similar pressure response, too. Region D is in the region Kuwata et al. previously discussed the existence of transient helices [34]. This is in good agreement with our observations of pressure responses typical for structured proteins. Interestingly, there is an overlap between region $\mathrm{B}$ and $\mathrm{C}$ of the pressure-sensible residues and a possible $\mathrm{pH}$-dependent aggregation site (residues 45-66) as described by Ralph Zahn [35]. The observed pressure-sensitivity emphasizes the importance of this region.

The probability that some residues of the unfolded part of $\operatorname{PrP}$ are in the time average in contact with the surface of the folded part is quite high and was discussed by Zahn $e t$ al. [19]. If this would be true it could also influence the pressure response of the folded core in full length PrP. Indeed, such a differential response is observed clearly for Glu168, His187, Thr192, Glu207, Glu211 and Tyr226. They show also different chemical shifts in truncated and full length PrP. From $\mathrm{C}^{\alpha}$ chemical shift differences in the full length and the truncated PrP Zahn et al. [19] identified as possible interaction regions His 187 to Thr193 and Glu219 to Tyr226. The differences in the pressure response observed may indicate a transient interaction between the region $\mathrm{D}$ that is closest in sequence to the core and the surface around amino acids mentioned above.

\section{Conclusion}

High-pressure NMR spectroscopy indicates that the folded core of the human prion protein occurs in two structural states $\mathrm{N}_{1}$ and $\mathrm{N}_{2}$ in solution associated with rather small differences in free enthalpies $(3.0 \mathrm{~kJ} / \mathrm{mol})$. At atmospheric pressure approximately $29 \%$ of the protein are already in the pressure favored conformation $\mathrm{N}_{2}$. There is a second process representing two possible folding intermediates $\mathrm{I}_{1}$ and $\mathrm{I}_{2}$ with average free enthalpy differences of $10.8 \mathrm{~kJ} /$ $\mathrm{mol}$ and $18.6 \mathrm{~kJ} / \mathrm{mol}$ respectively, which could represent a preaggregation state of the protein. Freezing out of such subpopulations by fixing them, e.g. with antibodies added or co-expressed in transgenic animals [50,51], has led to animal strains resistant against the development of prionosis. In this sense such local areas of high conformational variability/heterogeneity highlighted through high pressure NMR spectroscopy are indeed a first drug target for preventing the conversion into toxic intermediates able to transform into amyloid fibrils.

\section{Methods \\ Protein expression and sample preparation}

Recombinant human prion protein $h u \operatorname{PrP}(23-230)$ (residues 23 to 230) and $h u \operatorname{PrP}(121-230)$ (residues 121 to $230)$ was prepared as described previously $[19,52]$. Note that due to cloning artifacts the used recombinant proteins have two additional residues at the N-terminus (G21 and S22 in case of $h u \operatorname{PrP}(23-230), \mathrm{G} 119$ and S120 in case of $h u \operatorname{PrP}(121-230)$. For the NMR experiments a $1.1 \mathrm{mM}$ solution of ${ }^{15} \mathrm{~N}$-enriched $h u \operatorname{PrP}(23-230)$ and a $1.2 \mathrm{mM}$ solution of ${ }^{15} \mathrm{~N}$-enriched $h u \operatorname{PrP}(121-230)$ each in $10 \mathrm{mM}$ sodium acetate buffer $\mathrm{pH} 4.8$ was used. The measurements were performed in ${ }^{1} \mathrm{H}_{2} \mathrm{O}$ with $8 \%{ }^{2} \mathrm{H}_{2} \mathrm{O}$ added. The samples contained $0.1 \mathrm{mM}$ of 2,2-dimethyl-2-silapentane-5-sulfonate (DSS) as internal reference.

\section{High pressure NMR measurements}

All NMR experiments were carried out on a Bruker DRX 600 spectrometer, operating at $600 \mathrm{MHz}$ proton resonance frequency. To apply high pressure we used an online variable pressure cell system $[53,54]$ with a sapphire capillary of $1.72 \mathrm{~mm}$ inner and $3.14 \mathrm{~mm}$ outer diameter $[55,56]$. Spectra were recorded at hydrostatic pressures of $0.1,50,100,125,150,175$ and $200 \mathrm{MPa}$. At a temperature of $293 \mathrm{~K}$ and different pressures one-dimensional ${ }^{1} \mathrm{H}$ spectra and two-dimensional ${ }^{1} \mathrm{H}-{ }^{15} \mathrm{~N}$-TROSY spectra were acquired. The TROSY spectra [57] had a digital resolution of $2048 * 512$ points and a frequency width of $7184 *$ $1825 \mathrm{~Hz}$. All spectra were recorded and processed using the XWINNMR package from Bruker. AUREMOL [58,59] was used for peak picking, signal volume integration and analysis of the spectra.

\section{Analysis of the chemical shifts}

The spectra were assigned on basis of the assignment at ambient pressure [19]. The chemical shift values of the amide protons and nitrogen atoms in the TROSY spectra under the influence of pressure were fitted to equation (1), where $\delta_{0}$ is the chemical shift at ambient pressure $p_{0}$. The first order pressure coefficient $B_{1}$ and the second order pressure coefficient $B_{2}$ of each amide proton were corrected by subtracting the pressure coefficients of the standard peptide (Gly-Gly-X-Ala) of the corresponding amino acid as published by Arnold et al. [36]. For glutamate the coefficients of the C-terminal methylated peptide (GlyGly-Glu-Ala-methyl) were used $\left(B_{1} 0.53 \mathrm{ppm} / \mathrm{GPa}, B_{2}\right.$ $0.98 \mathrm{ppm} / \mathrm{GPa}^{2}$ ) [56]. The corrected coefficients are referred as $B_{1}{ }^{*}$ and $B_{2}{ }^{*}$.

$\delta\left(p, T_{0}\right)=\delta_{0}\left(p_{0}, T_{0}\right)+B_{1}\left(p_{0}, T_{0}\right)\left(p-p_{0}\right)+B_{2}\left(p_{0}, T_{0}\right)\left(p-p_{0}\right)^{2}$ (1)

If there is an equilibrium between two conformations of the protein that is in fast exchange on the time scale of the NMR experiment, the observed chemical shifts are the 
weighted average of the chemical shifts $\delta_{1}$ and $\delta_{2}$ of the two states as described by equation (2), with an equilibrium constant for the conformational exchange $K=\frac{N_{2}}{N_{1}}$.

$\delta=\frac{1}{1+K} \delta_{1} \frac{K}{1+K} \delta_{2}=\frac{\delta_{1}+\delta_{2} \exp \left(-\frac{\Delta G}{R T}\right)}{1+\exp \left(-\frac{\Delta G}{R T}\right)}=\delta_{1}+\left(\delta_{2}-\delta_{1}\right) \frac{1}{1+\exp \left(\frac{\Delta G}{R T}\right)}$

The free energy at ambient pressure $\Delta G_{0}$ can be determined by fitting the data to equation (3), which represents the first terms of a Taylor expansion of $\Delta G$ as function of pressure $p$ at constant temperature $T$. Here, $\Delta V$ is the partial molar volume and $\Delta \beta$ the compressibility. For our calculations of the $\Delta G_{0}$ values we neglected the quadratic term in equation (3).

$\Delta G=\Delta G_{0}+\Delta V\left(p-p_{0}\right)+\frac{1}{2} \Delta \beta\left(p-p_{0}\right)^{2}$

\section{Analysis of the signal volumes}

Is there a conformational exchange which is slow relative to the time scale of the NMR experiment, the signal volume of one state is proportional to its population. Assuming a two-state transition for the change of the conformational equilibrium with increased pressure, the equilibrium constant $K$ can be calculated from the relative cross-peak intensities of the TROSY spectra by equation (4) [34]. $I(p)$ is the relative cross-peak intensity at pressure $p$ and $I_{0}$ is the one, when $100 \%$ of the protein are in the native state. With this one obtains the free energy $\Delta G$ associated with the pressure-induced conformational change by equation (5). The free energy at ambient pressure $\Delta G_{0}$ is defined by equation (3) and can be obtained from a three parameter fit with $I_{0}, \Delta V_{0}$ and $\Delta G_{0}$ neglecting the second order term in $\mathrm{p}$.

$$
K=\frac{1-\frac{I(p)}{I_{0}}}{\frac{I(p)}{I_{0}}}
$$

$$
I(p)=\frac{I_{0}}{1+\exp \left(-\frac{\Delta G}{R T}\right)}
$$

\section{Analysis of pressure dependent shift correlations}

When the chemical shift changes in two samples A and B (e. g. the same spin in two constructs of a protein or the hydrogen and nitrogen atoms of an amide group) are governed by the same physical process that can be approximated by a two-site exchange then the chemical shift changes can be described by the same free energy $\Delta G$. In this case the pressure dependent chemical shift changes $\Delta \delta^{\mathrm{A}}$ and $\Delta \delta^{B}$

$$
\begin{aligned}
& \Delta \delta^{A}=\delta^{A}(p)-\delta^{A}\left(p_{0}\right)=\left(\delta_{2}{ }^{A}-\delta_{1}^{A}\right) f(p) \\
& \Delta \delta^{B}=\delta^{B}(p)-\delta^{B}\left(p_{0}\right)=\left(\delta_{2}^{B}-\delta_{1}^{B}\right) f(p)
\end{aligned}
$$

follow the linear relation

$$
\Delta \delta^{B}=\frac{\left(\delta_{2}{ }^{A}-\delta_{1}^{A}\right)}{\left(\delta_{2}{ }^{B}-\delta_{1}{ }^{B}\right)} \Delta \delta^{B} .
$$

\section{Authors' contributions}

WK and NK contributed equally to the manuscript. WK carried out the high pressure NMR experiments and the first analysis of the data and wrote a first version of the manuscript. NK finalized the data analysis, further developed the manuscript and created the manuscript figures. RZ provided structural data on PrP at ambient pressure. HRK conceived the study, participated in its design and was strongly involved into drafting the manuscript. All authors read and approved the final manuscript.

\section{Acknowledgements}

We thank Kurt Wüthrich for supporting this project and providing ${ }^{15} \mathrm{~N}$ enriched samples of huPrP, as well as Christine von Schroetter for protein production and purification. This work was supported by the Deutsche Forschungsgemeinschaft (Transregio-SFB "Membrane microdomains and their role in human disease").

\section{References}

I. Weissmann C, Enari M, Klohn PC, Rossi D, Flechsig E: Transmission of prions. PNAS 2002, 99(Suppl 4): 16378-16383.

2. Prusiner SB: Prions. PNAS 1998, 95:13363-13383.

3. Prusiner SB: Novel proteinaceous infectious particles cause scrapie. Science 1982, 216:136-144.

4. Bueler H, Aguzzi A, Sailer A, Greiner RA, Autenried P, Aguet M, Weissmann C: Mice devoid of PrP are resistant to scrapie. Cell 1993, 73:1339-1347.

5. Sailer A, Bueler H, Fischer M, Aguzzi A, Weissmann C: No propagation of prions in mice devoid of PrP. Cell 1994, 77:967-968.

6. Fischer M, Rulicke T, Raeber A, Sailer A, Moser M, Oesch B, Brandner $S$, Aguzzi A, Weissmann C: Prion protein (PrP) with aminoproximal deletions restoring susceptibility of PrP knockout mice to scrapie. EMBO ] 1996, I 5: I255-I264.

7. Horiuchi M, Caughey B: Prion protein interconversions and the transmissible spongiform encephalopathies. Structure Fold Des 1999, 7:R23I-R240.

8. Legname G, Baskakov IV, Nguyen HO, Riesner D, Cohen FE, DeArmond SJ, Prusiner SB: Synthetic mammalian prions. Science 2004, 305:673-676.

9. Collinge J: Prion diseases of humans and animals: their causes and molecular basis. Annu Rev Neurosci 200I, 24:5 I 9-550.

10. Prusiner SB, Scott M, Foster D, Pan KM, Groth D, Mirenda C, Torchia M, Yang SL, Serban D, Carlson GA, et al:: Transgenetic studies implicate interactions between homologous PrP isoforms in scrapie prion replication. Cell 1990, 63:673-686.

II. Chen SG, Gambetti P: A journey through the species barrier. Neuron 2002, 34:854-856.

12. Peretz D, Williamson RA, Legname G, Matsunaga $Y$, Vergara J, Burton DR, DeArmond SJ, Prusiner SB, Scott MR: A change in the conformation of prions accompanies the emergence of a new prion strain. Neuron 2002, 34:921-932. 
13. King CY, Diaz-Avalos R: Protein-only transmission of three yeast prion strains. Nature 2004, 428:319-323.

14. Tanaka M, Chien P, Naber N, Cooke R, Weissman JS: Conformational variations in an infectious protein determine prion strain differences. Nature 2004, 428:323-328.

15. Chien P, Weissman JS, DePace AH: Emerging principles of conformation-based prion inheritance. Annual Review of Biochemistry 2004, 73:617-656.

16. Vanik DL, Surewicz KA, Surewicz WK: Molecular basis of barriers for interspecies transmissibility of mammalian prions. Mol Cell 2004, 14:139-145.

17. James TL, Liu H, Ulyanov NB, Farr-Jones S, Zhang H, Donne DG, Kaneko K, Groth D, Mehlhorn I, Prusiner SB, et al.: Solution structure of a I42-residue recombinant prion protein corresponding to the infectious fragment of the scrapie isoform. PNAS 1997, 94:10086-10091.

18. Donne DG, Viles JH, Groth D, Mehlhorn I, James TL, Cohen FE, Prusiner SB, Wright PE, Dyson HJ: Structure of the recombinan full-length hamster prion protein $\operatorname{PrP}(29-231)$ : the $\mathbf{N}$ terminus is highly flexible. PNAS 1997, 94: |3452-|3457.

19. Zahn R, Liu A, Luhrs T, Riek R, von Schroetter C, Lopez GF, Billeter $M$, Calzolai L, Wider G, Wuthrich K: NMR solution structure of the human prion protein. PNAS 2000, 97:|45-I50.

20. Calzolai L, Zahn R: Influence of pH on NMR Structure and Stability of the Human Prion Protein Globular Domain. J Biol Chem 2003, 278:35592-35596.

21. Knaus KJ, Morillas M, Swietnicki W, Malone M, Surewicz WK, Yee VC: Crystal structure of the human prion protein reveals a mechanism for oligomerization. Nat Struct Biol 200I, 8:770-774

22. Lopez GF, Zahn R, Riek R, Wuthrich K: NMR structure of the bovine prion protein. PNAS 2000, 97:8334-8339.

23. Hornemann $S$, Glockshuber R: A scrapie-like unfolding intermediate of the prion protein domain $\operatorname{PrP}(|2|-23 \mid)$ induced by acidic pH. PNAS 1998, 95:6010-6014.

24. Jackson GS, Hosszu LL, Power A, Hill AF, Kenney J, Saibil H, Craven C], Waltho JP, Clarke AR, Collinge J: Reversible conversion of monomeric human prion protein between native and fibrilogenic conformations. Science 1999, 283:1935-1937.

25. Inoue K, Yamada H, Akasaka K, Herrmann C, Kremer W, Maurer T, Doker R, Kalbitzer HR: Pressure-induced local unfolding of the Ras binding domain of RaIGDS. Nat Struct Biol 2000, 7:547-550.

26. Foguel $D$, Silva $\mathrm{J}$ : New insights into the mechanisms of protein misfolding and aggregation in amyloidogenic diseases derived from pressure studies. Biochemistry 2004 43: $11361-11370$.

27. Silva JL, Foguel $D$, Royer CA: Pressure provides new insights into protein folding, dynamics and structure. Trends Biochem Sci 200I, 26:612-618

28. Kamatari YO, Kitahara R, Yamada H, Yokoyama S, Akasaka K: Highpressure NMR spectroscopy for characterizing folding intermediates and denatured states of proteins. Methods 2004, 34:133-143.

29. Torrent J, Alvarez-Martinez MT, Heitz F, Liautard JP, Balny C, Lange $\mathrm{R}$ : Alternative prion structural changes revealed by high pressure. Biochemistry 2003, 42:1318-1325.

30. Torrent J, Alvarez-Martinez MT, Harricane MC, Heitz F, Liautard JP, Balny $C$, Lange R: High pressure induces scrapie-like prion protein misfolding and amyloid fibril formation. Biochemistry 2004 43:7|62-7|70

31. Torrent J, Alvarez-Martinez MT, Liautard JP, Balny C, Lange R: The role of the $132-160$ region in prion protein conformational transitions. Protein Sci 2005, 14:956-967.

32. Cordeiro Y, Kraineva J, Ravindra R, Lima LM, Gomes MPB, Foguel D, Winter R, Silva LL: Hydration and packing effects on prion folding and \{beta\}-sheet conversion: high pressure spectroscopy and pressure perturbation calorimetry studies. I Biol Chem 2004, 279:32354-32359.

33. Martins SM, Chapeaurouge A, Ferreira ST: Folding intermediates of the prion protein stabilized by hydrostatic pressure and low temperature. J Biol Chem 2003, 278:50449-50455.

34. Kuwata K, Li H, Yamada H, Legname G, Prusiner SB, Akasaka K, James TL: Locally disordered conformer of the hamster prion protein: a crucial intermediate to PrPSc? Biochemistry 2002, 4I:12277-12283.
35. Zahn R: The octapeptide repeats in mammalian prion protein constitute a pH-dependent folding and aggregation site. J Mol Biol 2003, 334:477-488.

36. Arnold MR, Kremer W, Ludemann HD, Kalbitzer HR: IH-NMR parameters of common amino acid residues measured in aqueous solutions of the linear tetrapeptides Gly-Gly-X-Ala at pressures between $\mathbf{0 . 1}$ and $200 \mathrm{MPa}$. Biophys Chem 2002, 96:129-140.

37. Maurer T, Meier S, Kachel N, Munte CE, Hasenbein S, Koch B, Hengstenberg W, Kalbitzer HR: High-resolution structure of the Histidine-Containing Phosphocarrier Protein (HPr) from Staphylococcus aureus and characterization of its interaction with the bifunctional HPr Kinase/Phosphorylase. J Bacteriol 2004, 1 86:5906-59|8.

38. Stanley EM, Batten RC: Viscosity of water at high pressures and moderate temperatures. J Phys Chem 1969, 73:I 187-II91.

39. Akasaka K, Li H: Low-lying excited states of proteins revealed from nonlinear pressure shifts in IH and I5N NMR. Biochemistry 200I, 40:8665-867I.

40. Castilla J, Saa P, Hetz C, Soto C: In vitro generation of infectious scrapie prions. Cell 2005, I 2 I:195-206.

4I. Tanaka M, Chien P, Yonekura K, Weissman JS: Mechanism of cross-species prion transmission: An infectious conformation compatible with two highly divergent yeast prion proteins. Cell 2005, I $21: 49-62$.

42. Jones EM, Surewicz WK: Fibril conformation as the basis of species- and strain-dependent seeding specificity of mammalian prion amyloids. Cell 2005, I $21: 63-72$.

43. Baskakov IV, Legname G, Baldwin MA, Prusiner SB, Cohen FE: Pathway complexity of prion protein assembly into amyloid. J Biol Chem 2002, 277:21।40-2।I48.

44. Schwarzinger S, Kroon GJ, Foss TR, Chung J, Wright PE, Dyson HJ: Sequence-dependent correction of random coil NMR chemical shifts. J Am Chem Soc 200 I, 1 23:2970-2978.

45. Wille H, Michelitsch MD, Guenebaut V, Supattapone S, Serban A, Cohen FE, Agard DA, Prusiner SB: Structural studies of the scrapie prion protein by electron crystallography. PNAS 2002, 99:3563-3568.

46. Govaerts C, Wille H, Prusiner SB, Cohen FE: Evidence for assembly of prions with left-handed \{beta\}-helices into trimers. PNAS 2004:0402254I0I.

47. Hummer G, Garde S, Garcia AE, Paulaitis ME, Pratt LR: The pressure dependence of hydrophobic interactions is consistent with the observed pressure denaturation of proteins. PNAS 1998, 95:1552-1555.

48. Nicholson EM, Mo H, Prusiner SB, Cohen FE, Marqusee S: Differences between the prion protein and its homolog Doppel: a partially structured state with implications for scrapie formation. J Mol Biol 2002, 316:807-815.

49. Hosszu LL, Baxter NJ, Jackson GS, Power A, Clarke AR, Waltho JP, Craven C], Collinge J: Structural mobility of the human prion protein probed by backbone hydrogen exchange. Nat Struct Biol 1999, 6:740-743.

50. Heppner FL, Musahl C, Arrighi I, Klein MA, Rulicke T, Oesch B, Zinkernagel RM, Kalinke U, Aguzzi A: Prevention of scrapie pathogenesis by transgenic expression of anti-prion protein antibodies. Science 200I, 294:I78-182.

51. Peretz D, Williamson RA, Kaneko K, Vergara J, Leclerc E, SchmittUlms G, Mehlhorn IR, Legname G, Wormald MR, Rudd PM, et al.: Antibodies inhibit prion propagation and clear cell cultures of prion infectivity. Nature 200I, 4 I 2:739-743.

52. Zahn R, von Schroetter C, Wuthrich K: Human prion proteins expressed in Escherichia coli and purified by high-affinity column refolding. FEBS Lett 1997, 417:400-404.

53. Yamada $\mathrm{H}$ : Pressure-resisting glass cell for high pressure, high resolution NMR measurement. Rev Sci Instrum 1974, 45:640-642.

54. Price WE, Ludemann HD: NMR and diaphragm cell techniques for the study of molecular dynamics in fluids. In High Pressure Techniques in Chemistry and Physics: A Practical Approach Edited by: Holzapfel WB, Isaacs NS. Oxford: Oxford University Press; 1997:225

55. Arnold MR, Kalbitzer HR, Kremer W: High-sensitivity sapphire cells for high pressure NMR spectroscopy on proteins. J Magn Reson 2003, |61:|27-|3| 
56. Kremer W, Arnold MR, Kachel N, Kalbitzer HR: The use of highsensitivity sapphire cells in high pressure NMR spectroscopy and its application to proteins. Spectroscopy 2004, I 8:27I -278.

57. Pervushin K, Riek R, Wider G, Wuthrich K: Attenuated T2 relaxation by mutual cancellation of dipole-dipole coupling and chemical shift anisotropy indicates an avenue to NMR structures of very large biological macromolecules in solution. PNAS 1997, 94:12366-12371.

58. Gronwald W, Kalbitzer HR: Automated structure determination of proteins by NMR spectroscopy. Prog Nucl Mag Res Sp 2004, 44:33-96.

59. AUREMOL Homepage [http://www.auremol.de]

60. Koradi R, Billeter M, Wuthrich K: MOLMOL: a program for display and analysis of macromolecular structures. J Mol Graph 1996, I 4:51-32.

Publish with Bio Med Central and every scientist can read your work free of charge

"BioMed Central will be the most significant development for disseminating the results of biomedical research in our lifetime. "

Sir Paul Nurse, Cancer Research UK

Your research papers will be:

- available free of charge to the entire biomedical community

- peer reviewed and published immediately upon acceptance

- cited in PubMed and archived on PubMed Central

- yours - you keep the copyright

Submit your manuscript here:

http://www.biomedcentral.com/info/publishing_adv.asp
BiolMedcentral 